This is the pre-peer reviewed version of the following article:

Ichikawa R.U., Roca A.G., López-Ortega A., Estrader M., Peral I., Turrillas X., Nogués J.. Combining X-Ray Whole Powder Pattern Modeling, Rietveld and Pair Distribution Function Analyses as a Novel Bulk Approach to Study Interfaces in Heteronanostructures: Oxidation Front in $\mathrm{FeO} / \mathrm{Fe} 3 \mathrm{O} 4$ Core/Shell Nanoparticles as a Case Study. Small, (2018). 14. 1800804: - . 10.1002/smll.201800804,

which has been published in final form at https://dx.doi.org/10.1002/smll.201800804. This article may be used for non-commercial purposes in accordance with Wiley Terms and Conditions for Use of Self-Archived Versions. 


\section{Combining X-ray Whole Powder Pattern Modeling, Rietveld and Pair Distribution Function analyses as a novel bulk approach to study interfaces in heteronanostructures: Oxidation front in $\mathrm{FeO} / \mathrm{Fe}_{3} \mathrm{O}_{4}$ core/shell nanoparticles as a case study}

Rodrigo U. Ichikawa, Alejandro G. Roca, Alberto López-Ortega, Marta Estrader, Inma Peral, Xabier Turrillas and Josep Nogués

Rodrigo U. Ichikawa

IPEN-Instituto de Pesquisas Energéticas e Nucleares, Av. Prof. Lineu Prestes, 2242 - Cidade Universitária, São Paulo, SP, 05508-000, Brazil

Dr. Alejandro G. Roca, Dr. Marta Estrader ${ }^{\gamma}$, Prof. Josep Nogués

Catalan Institute of Nanoscience and Nanotechnology (ICN2), CSIC and BIST, Campus UAB, Bellaterra, Barcelona, E-08193, Spain.

'Present Address: LPCNO, Université de Toulouse, CNRS, INSA, UPS, 135 avenue de Rangueil, Toulouse, F-31077, France

Dr. Alberto López-Ortega

CIC nanoGUNE, Tolosa Hiribidea, 76, Donostia-San Sebastian, E-20018, Spain.

Dr. Inma Peral

ALBA Synchrotron, Carrer de la Llum, 2-26, Cerdanyola del Vallés, Barcelona, E-08290 Spain.

Physics and Materials Science Research Unit, University of Luxembourg, L-1511 Luxembourg.

Materials Research and Technology Department, Luxembourg Institute of Science and Technology, L-4422 Belvaux, Luxembourg.

Dr. Xabier Turillas

ALBA Synchrotron, Carrer de la Llum, 2-26, Cerdanyola del Vallés, Barcelona, E-08290 Spain.

Institut de Ciència de Materials de Barcelona- CSIC, UAB Campus, Cerdanyola del Vallès, Barcelona, E-08193, Spain

Prof. Josep Nogués

ICREA, Pg. Lluís Companys 23, Barcelona, E-08010, Spain

Keywords: core/shell nanoparticles, interfaces, iron oxides, X-ray diffraction, Whole Powder Pattern Modeling, Rietveld, pair distribution function.

Understanding the microstructure in heterostructured nanoparticles is crucial to harnessing their functional properties. Although microscopy methods are ideal for this purpose, they 
typically allow analyzing only a few nanoparticles. Thus, there is an increasing need for structural methods which take the whole sample into account, giving averaged information of the material. Here we present a novel bulk approach based on the systematic analysis of X-ray powder diffraction patterns. The temporal evolution of the microstructure of $\mathrm{FeO} / \mathrm{Fe}_{3} \mathrm{O}_{4}$ core/shell nanocubes has been studied by synchrotron X-ray powder diffraction at different time intervals (over a four-year period). The corresponding diffraction patterns have been carefully analyzed by combining whole powder pattern modeling, Rietveld and pair distribution function approaches. The results indicate that a two-phase approach (i.e., FeO and $\mathrm{Fe}_{3} \mathrm{O}_{4}$ ) is not sufficient to successfully fit the data and two additional interface phases ( $\mathrm{FeO}$ and $\mathrm{Fe}_{3} \mathrm{O}_{4}$ ) are needed to obtain satisfactory fits. Thus, the sample is modeled as a $\mathrm{Fe}_{3} \mathrm{O}_{4}-$ outer shell/ $\mathrm{Fe}_{3} \mathrm{O}_{4}$-inner shell/FeO-outer core/FeO-inner core onion-type structure. The analysis shows that the $\mathrm{Fe}_{3} \mathrm{O}_{4}$ phases grow to some extent ( $1 \mathrm{~nm}$ in thickness) with time at the expense of the $\mathrm{FeO}$ core. Moreover, the $\mathrm{FeO}$ core progressively changes its stoichiometry to accommodate more oxygen. The temporal evolution of the parameters indicates that the structure of the $\mathrm{FeO} / \mathrm{Fe}_{3} \mathrm{O}_{4}$ nanocubes is rather stable (in concordance with the passivation layer role of $\mathrm{Fe}_{3} \mathrm{O}_{4}$ ), although the exact interface structure may slightly evolve with time. This novel approach paves the way for average studies of interfaces in different kinds of heterostructured nanoparticles, particularly in cases where spectroscopic methods may have some limitations (e.g., different oxidation states of the same ion or polymorphs of the same phase).

\section{Introduction}


The interest in hybrid structures comprising two (or more) inorganic materials is continuously rising. The different properties of the constituents (e.g., catalytic, optic, magnetic, or biomedical) confers the material a multifunctional character, often with unique and enhanced properties, which can be accurately controlled by the growth parameters (i.e., size, shape and material composition) ${ }^{[1-3]}$ In this type of materials, interfaces are of particular relevance since not only do they determine the growth of the parts, but they can also be used as an additional parameter to tune the properties through interface interactions. ${ }^{[4-7]}$ In particular, interface diffusion, i.e., intermixing, may have significant consequences in the overall properties of the materials. ${ }^{[8-11]}$ However, despite the great potential of this type of structures, the structural characterization of interfaces at the nanoscale remains a challenge. Although transmission electron microscopy (TEM) and scanning TEM (STEM) imaging, particularly when combined with electron energy loss spectroscopy (EELS) analysis, can give an accurate account of the morphology and composition of the particles, ${ }^{[12-14]}$ they have the drawback that typically only a small number of particles can be analyzed. Thus, novel approaches to investigate the structure of core/shell nanoparticles using "bulk" methods are being proposed, such as anomalous small angle X-ray scattering (ASAXS), ${ }^{[15]} \mathrm{X}$-ray magnetic circular dichroism $(\mathrm{XMCD})^{[16]}$ or resonant inelastic X-ray spectroscopy (RIXS) with MCD analysis. ${ }^{[8]}$ However, when only one type of ion is involved in the structure (e.g., different oxidation states of the same ion, e.g., $\mathrm{FeO} / \mathrm{Fe}_{3} \mathrm{O}_{4}$ core/shell nanoparticles ${ }^{[17]}$ or different polymorphs of the same compound, e.g. $\gamma-\mathrm{Fe}_{2} \mathrm{O}_{3}$ vs. $\varepsilon-\mathrm{Fe}_{2} \mathrm{O}_{3}{ }^{[18]}$ ) the characterization by STEM-EELS, RIXSMCD or ASAXS remains rather complex. This stems from the fact that in spectroscopy-based methods it may not be straightforward to separate the contribution of the different oxidations states/polymorphs of the same ion, although the appropriate fitting of the spectra can give valuable information. ${ }^{[19,20]}$ Interestingly, since diffraction methods are sensitive to the crystalline structures rather than to the oxidation states (e.g., while $\mathrm{FeO}$ has a rock salt 
structure, $\mathrm{Fe}_{3} \mathrm{O}_{4}$ is a cubic spinel), they may offer renewed potential for the analysis of hybrid nanoparticles.

Here we demonstrate that the in-depth analysis of the X-ray powder diffraction (XRD) of heterostructured nanoparticles can give insightful information about the microstructure of the system. As a case of study, the time evolution (over several years) of the interface between $\mathrm{FeO}$ and $\mathrm{Fe}_{3} \mathrm{O}_{4}$ in $\mathrm{FeO} / \mathrm{Fe}_{3} \mathrm{O}_{4}$ core/shell nanoparticles has been quantitatively analyzed by combining X-ray synchrotron diffraction techniques as Whole Powder Pattern Modelling (WPPM), Rietveld refinement and Pair Distribution Function (PDF). The results confirm the passivation-layer role of the $\mathrm{Fe}_{3} \mathrm{O}_{4}$ surface layer and evidence the presence of a prominent interface (probably with an oxygen gradient) between the $\mathrm{FeO}$ core and the $\mathrm{Fe}_{3} \mathrm{O}_{4}$ shell.

Note that $\mathrm{FeO} / \mathrm{Fe}_{3} \mathrm{O}_{4}$ core/shell nanoparticles are a subject of considerable current interest both due to their appealing magnetic properties (e.g., tunable exchange bias or the presence of both a Néel and a Verwey transitions $)^{[17,21]}$ and their potential applications (e.g., magnetic hyperthermia, magnetic bioassays, microwave absorbers, anode materials for Li-ion batteries or solar hydrogen production via water-splitting). ${ }^{[22-27]}$

\section{Results and discussion}

As can be seen in Figure 1a and b (and Figure S1) the as-synthesized nanoparticles (sample NC2013) exhibit a clear cubic-like morphology with an average edge length of $32 \mathrm{~nm}$ and a narrow particle size-shape distribution (standard deviation, $\sigma=3 \mathrm{~nm}$; lognorm polydispersity index of 0.1 ), typical of nanoparticles synthesized by thermal decomposition. Note that the characteristic shape is the result of the selective binding of oleate ligands into $\{100\}$ facets in a synthesis with a thermodynamic control growth regime. ${ }^{[28]}$ 
Typical lattice fringes from wüstite and magnetite can be observed in the core and the shell of the particle, respectively. Families of planes with an interplanar distance of $2.18 \AA$ and $2.94 \AA$ can be attributed to the (200) and (220) planes of $\mathrm{FeO}$ and $\mathrm{Fe}_{3} \mathrm{O}_{4}$, respectively (Figure 1c), as confirmed by the Fast Fourier Transforms of the image, where $\mathrm{FeO}$ and $\mathrm{Fe}_{3} \mathrm{O}_{4}$ spots can be identified (Figure 1d). Importantly, the particles are clearly separated from each other due to the surfactant capping layer composed of oleic acid and oleate molecules, which leads to an interparticle space of 3-4 nm.

The X-ray synchrotron diffraction profiles of the sample measured at different times can be indexed by rock salt (w) and cubic spinel (m) peaks (Figure 2), consistent with the expected $\mathrm{FeO}$ and $\mathrm{Fe}_{3} \mathrm{O}_{4}$ phases, respectively. Moreover, it can be seen that the relative amount of $\mathrm{Fe}_{3} \mathrm{O}_{4}$ increases with time (as most clearly seen by the relative intensity of the $(442)_{\mathrm{m}}$ and $(022)_{\mathrm{w}}$ peaks at about $4.2 \AA^{-1}$; highlighted in light blue in Figure 2). For the NC2013 sample a small Fe impurity can be observed in the pattern ( $3 \%$ in weight), which probably arises from the early stages of the $\mathrm{FeO}$ disproportionation $\left(4 \mathrm{FeO} \rightarrow \mathrm{Fe}+\mathrm{Fe}_{3} \mathrm{O}_{4}\right)$, which quickly oxidizes to $\mathrm{Fe}_{3} \mathrm{O}_{4}$.

It is well-known that bulk $\mathrm{FeO}$ is not stable and it oxidizes to $\mathrm{Fe}_{3} \mathrm{O}_{4}$ or $\gamma-\mathrm{Fe}_{2} \mathrm{O}_{3}$. ${ }^{\text {[29] }}$ However, in nanoparticle form usually the surface oxidation of $\mathrm{FeO}$ to $\mathrm{Fe}_{3} \mathrm{O}_{4}$ results in a passivation layer, which to a certain extent prevents, or at least slows down, the full oxidation of the particles. This leads to the characteristic $\mathrm{FeO} / \mathrm{Fe}_{3} \mathrm{O}_{4}$ core/shell structure in this system, both in cubic ${ }^{[14,17,21,30,31]}$ and spherical ${ }^{[22,32-34]}$ morphologies, and in similar systems (i.e., rock salt/spinel). ${ }^{[35-38]}$ Note that oxidation of $\mathrm{FeO}$ towards $\mathrm{Fe}_{3} \mathrm{O}_{4}$ seems to be more pronounced in spherical particles than in cubic ones. ${ }^{[32,33,39]}$ The transformation of wüstite $\left(\mathrm{Fe}_{\mathrm{x}} \mathrm{O}\right)$ to magnetite $\left(\mathrm{Fe}_{3} \mathrm{O}_{4}\right)$ occurs through topotaxial growth over shared planes of both iron oxide phases. ${ }^{[31,38]}$ The oxidation starts with the adsorption of oxygen on the $\mathrm{Fe}_{\mathrm{x}} \mathrm{O}$ surface leading to an inward oxygen potential gradient and an outward diffusion of $\mathrm{Fe}(\mathrm{II})$ 
cations. The wüstite-to-magnetite phase transformation starts with the generation of an interface featured by the rearrangement of the cations through the two phases maintaining a simple topotaxial orientation relationship ${ }^{[40]}$ between the $(200)_{\mathrm{w}} / /(400)_{\mathrm{m}}$ and $(220)_{\mathrm{w}} / /(440)_{\mathrm{m}}$ planes. ${ }^{[31]}$ Taking advantage of the equivalent fcc $\mathrm{O}^{2-}$ sublattice in both structures, the octahedral sublattice is extended over the equivalent planes of the both phases, where the topotaxial transformation occurs. Subsequently, an inward displacement of the wüstitemagnetite interface takes place, preserving the orientation of the two phases, ${ }^{[41]}$ so that the homogeneous and long-range order structure in these directions is maintained. Conversely, new tetrahedral order is generated accommodating Fe(III) cations and creating new family planes characteristic of magnetite, e.g. (220). These magnetite planes which are not shared with the wüstite structure are constrained in the shell region, leading to dislocations and antiphase boundaries at the interface. As the oxidation process continues the subsequent evolution occurs in a non-homogenous manner into the particles, forming small subdomains with the presence of a high number of defects. This forces the creation of a substantial number of crystallite boundaries ${ }^{[41]}$, leading the formation of a mosaic texture which explains the limited structural coherence in the XRD patterns, which do not resemble those of a pure magnetite structure.

In the particular case of $\mathrm{FeO} / \mathrm{Fe}_{3} \mathrm{O}_{4}$, the formation of antiphase boundaries has been reported to occur during the topotaxial formation of $\mathrm{Fe}_{3} \mathrm{O}_{4}$, which may stabilize the core/shell structure, inhibiting the full oxidation of the nanoparticles. ${ }^{[31]}$ Closer inspection at the individual peaks (even those pertaining only to rock salt or cubic inverse spinel) reveals that the shape of the peaks does not display a symmetrical peak shape. This hints that the peaks (even those pertaining to a single phase) are heavily affected by size and shape of the crystallites. For this reason, reciprocal-space Whole Powder Pattern Modelling $^{[42]}$ (WPPM) was chosen to perform the structural study of our system, where size, shape and strain of the crystallites can be modelled. WPPM is particularly suited to deal 
with small crystallites when these parameters need to be taken into account. Note that although real-space methods, like Debye function analysis, are being increasingly applied for the analysis of microstructural parameters ${ }^{[43]}$, they are far from ideal for large particles like ours since calculating the Debye scattering equation, especially when defects are present, can be extremely time consuming. ${ }^{[44]}$

For the modelling, first a NIST SRM Si 640d reference sample was refined to obtain a parametric description of the Instrumental Profile (IP), which corrects the main aberrations affecting XRD powder profiles. Note that this is important to guarantee that only the contribution related to the sample (size, shape and strain) are being analyzed. The instrumental profile was modelled using a pseudo-Voigt function. The parameters of the instrumental function were then kept fixed for all the modelling procedure. In addition, a profile measured with an empty capillary was subtracted from all the profiles of the samples, again to guarantee that only contributions related to the structural features of the studied nanosystem are being considered in the study. However, attempts to fit the whole pattern with only two phases $\left(\mathrm{FeO}\right.$ and $\left.\mathrm{Fe}_{3} \mathrm{O}_{4}\right)$ result in rather large errors (see Figure 3a). Note that it is well-known that different crystallite shapes ${ }^{[42,45]}$ and $\operatorname{strain}^{[46,47]}$ can lead to a peak asymmetry. Thus, to account for this effect, crystallites of different shapes (e.g., cubic and spherical) with a strain model were tried for the $\mathrm{FeO}$ and $\mathrm{Fe}_{3} \mathrm{O}_{4}$ phases in the WPPM analysis. Nevertheless, the two-phase model could not account for the experimental pattern even when considering the crystallite shape and strain. On the other hand, based on the structure of the particle and the oxidation process of $\mathrm{FeO}$ (see above), it is plausible to assume that there exists an interface layer, with structural parameters (e.g., lattice parameter) slightly different from those of the core or shell counterparts, which contributes sufficiently to the XRD to distort the shape of the peaks, also contributing to its asymmetry. Note that given the relatively large size of the particles, the contribution to the XRD pattern of a thin intermediate layer may be not at all negligible. Besides, given the analogous TEM microstructure reported 
for cubic $\mathrm{FeO} / \mathrm{Fe}_{3} \mathrm{O}_{4}$ nanoparticles in the $20-50 \mathrm{~nm}$ range, ${ }^{[2,17,27,28,48]}$ one may expect similar interface layers to form for a range of nanoparticle sizes. Thus, we refined the profile by introducing one additional cubic spinel phase (similar to what has been proposed by Pichon et al. ${ }^{[30]}$, so a total of three phases was considered: the original $\mathrm{Fe}_{3} \mathrm{O}_{4}$ phase, the $\mathrm{FeO}$ phase and a second $\mathrm{Fe}_{3} \mathrm{O}_{4}$ phase. However, although the fits certainly improved, the results were still not satisfactory (see Figure 3b). With the introduction of a second wüstite phase the modelling clearly improved, as can be seen in Figures $3 \mathrm{c}$ and S2. Hence, the final analysis was performed using two cubic spinel and two wüstite phases, which results in a reasonable fit (as evidenced by the small difference between the experimental and the fit data). It is important to point out that the inclusion of additional phases did not significantly improve quality of the fit. Consequently, four phases were chosen to avoid "overfitting" the experimental data. The phases are termed as $\mathrm{Fe}_{3} \mathrm{O}_{4}$-outer shell/ $\mathrm{Fe}_{3} \mathrm{O}_{4}$-inner shell/FeO-outer core/FeO-inner core, i.e., forming stacking layers of a nanocube in an onion-type structure. Namely, we assign each of the four fitted phases to a specific layer in the onion-structure considering that each layer is not a slab but that it is composed of crystallites (see Figure 3d). To carry out the analysis of the evolution of the microstructure, first WPPM was used taking into account the four layers, in an "onion-type" structure. For the modelling, it was assumed that each phase was composed of spherical crystallites with a log-normal size distribution. For the refinements, the cell parameters for the $\mathrm{Fe}_{3} \mathrm{O}_{4}$ phases were allowed to vary $\pm 10 \%$ from the values obtained from a previous work with similar nanocubes. ${ }^{[17]}$ Note that this was adopted since $\mathrm{Fe}_{3} \mathrm{O}_{4}$ is very stable and its cell parameter is not expected to vary greatly. The main values obtained from the WPPM analysis are presented in Table 1 and Figure 4.

From Figure 4 and Table 1 it can be seen that most of the parameters of the structure evolve with time. For example, the cell parameters of the two $\mathrm{FeO}$ phases are markedly different and present a clear temporal evolution. It is well-known that the cell 
parameter of $\mathrm{FeO}$ depends strongly on the oxygen content, $\mathrm{Fe}_{\mathrm{x}} \mathrm{O}$. In fact, in bulk it has been demonstrated that the lattice parameter can be used to calculate the iron content (x) for the $\mathrm{Fe}_{\mathbf{x}} \mathrm{O}$ phase, using the $\mathbf{0 . 3 8 5 6 + 0 . 0 4 7 8} \cdot \mathbf{x}$ relation. ${ }^{[49]}$ The results indicate in the fresh sample, that $\mathrm{FeO}$ core is close to stoichiometric $\mathrm{FeO}, \mathrm{Fe}_{0.92} \mathrm{O}$, while the outer core has a composition of $\mathrm{Fe}_{0.79} \mathrm{O}$. The use of two phases for wüstite evidences the oxidation mechanism of $\mathrm{FeO}$ where there is a diffusion of vacancies towards the interface between wüstite and magnetite and cations towards the core center. ${ }^{[30,37,38]}$ In fact, we used the different oxidation degree of the $\mathrm{FeO}$ phases to assign the one closer to stoichiometric $\mathrm{FeO}$ to the inner core. Moreover, as times advances both $\mathrm{FeO}$ phases become oxidized leading to stoichiometries further away from $\mathrm{FeO}$ and closer to $\mathrm{Fe}_{3} \mathrm{O}_{4}$ (although preserving the rock salt structure). These results seem to indicate that the oxidation of the $\mathrm{FeO}$ core evolves slowly inwards from the surface. Indeed, the temporal evolution tends to diminish the cell parameter of both $\mathrm{FeO}$ phases, thus, the cell mismatch at the $\mathrm{FeO} / \mathrm{Fe}_{3} \mathrm{O}_{4}$ interphase (i.e., from $0.86 \%$ to $0.52 \%$ for the outer $\mathrm{FeO}$ core and inner $\mathrm{Fe}_{3} \mathrm{O}_{4}$ shell). This effect can be ascribed to the formation of a graded interface between the inner core and outer $\mathrm{Fe}_{3} \mathrm{O}_{4}$ shell which should reduce the defects formed during the topotaxial transformation.

When evaluating the crystallite sizes of the FeO phases (Table 1 and insets in Figure 4), it can be seen that while the size of the $\mathrm{FeO}$ inner core becomes progressively smaller, the one for the outer core increases. The change in stoichiometry and size of the outer $\mathrm{FeO}$ core probably indicates that this interface layer is evolving to eventually become $\mathrm{Fe}_{3} \mathrm{O}_{4}$. Thus, probably this phase tends to follow the structure of $\mathrm{Fe}_{3} \mathrm{O}_{4}$ inner shell rather than the one of the inner $\mathrm{FeO}$ core. However, given the unusual shape of the phases, crystallite sizes can be misleading to fully characterize the shell(s) morphology. Thus, using cell parameters values and relative intensities from WPPM as starting parameters, Rietveld refinement was applied to the X-ray synchrotron 
diffraction data to quantify the weight percent of each phase and refine cell parameters and a global atomic displacement factors (see Table S1). From the weight percent (V) and assuming a cube with different shells (Figure 3d), it is possible to estimate a thickness, $t_{i}$, of each phase (see Table 2, calculated using a total edge length of $32 \mathrm{~nm}$, as obtained from TEM).

For the FeO inner core, when comparing the crystallite size (D) with its thickness $\left(2 \times t_{\mathrm{FeO}} \mathrm{IC}\right)$ it can be seen that in the fresh sample they are similar. Note that the difference between both values can be partially accounted by the number- vs. volumeweighted character of the TEM and XRD data, respectively. ${ }^{[50]}$. However, as time progresses the crystallite size becomes smaller, while the thickness remains roughly constant. This indicates that in the fresh sample the inner core was highly crystalline, which breaks into smaller crystallites as a result of the oxygen penetration, although the whole volume of this phase remains essentially unaltered. The constrained oxidation of the spinel phase over the pre-existing FeO structure occurs through the concomitant increase of the elastic strain, forming dislocations that move and assemble as the reaction progresses, destroying the crystallinity of the pristine FeO phase. For the outer $\mathrm{FeO}$ core, the crystallite size increases followed by a thickness increase with time. This tentatively implies that the outer $\mathrm{FeO}$ core phase is structurally more ordered with time. Moreover, its stoichiometry, close to that of $\mathrm{Fe}_{3} \mathrm{O}_{4}$, may indicate that the outer $\mathrm{FeO}$ core may be close to becoming $\mathrm{Fe}_{3} \mathrm{O}_{4}$. Overall, the volume of the $\mathrm{FeO}$ structure (inner + outer core) decreases indicating that the $\mathrm{Fe}_{3} \mathrm{O}_{4}$ shell part must be growing as a consequence of the oxidation process at the expense of $\mathrm{FeO}$.

In the case of $\mathrm{Fe}_{3} \mathrm{O}_{4}$ it is less obvious than for $\mathrm{FeO}$ how to assign each phase to the inner or outer shell. Since it is well accepted that the lattice parameter of $\mathrm{Fe}_{3-\delta} \mathrm{O}_{4}$ decreases as it becomes more oxidized, ${ }^{[51]}$ it could be expected that the outer shell (probably more oxidized) would have a smaller lattice parameter. However, the lattice 
parameter of the two $\mathrm{Fe}_{3} \mathrm{O}_{4}$ shells is virtually identical (Table 1), thus, in this case this argument is perhaps not so reliable. Hence, finally, we allocated the phase with the largest relative volume to the outer shell since for a given shell thickness the volume contribution will be much larger in the outer shell. When looking at the crystallite size of the two $\mathrm{Fe}_{3} \mathrm{O}_{4}$ shells it can be seen that the outer shell has a crystallite size that remains rather small and roughly constant, while the inner shell has a non-monotonic evolution of the crystallite size. Moreover, when analyzing the time evolution of the respective thicknesses, although compared to the fresh sample the outer shell decreases and the inner shell increases, the behavior is somewhat irregular. This suggests that the interface structure may not be stable with time and that oxygen may be mobile, slightly altering the exact inner structure of the nanoparticle, although we cannot rule out a partial oxidation of the outer shell to $\gamma-\mathrm{Fe}_{2} \mathrm{O}_{3}$. Moreover, it has to be taken into account that for simplicity we assumed the interface between the inner $\mathrm{FeO}$ core and the outer $\mathrm{Fe}_{3} \mathrm{O}_{4}$ shell has two distinct phases $\left(\mathrm{FeO}+\mathrm{Fe}_{3} \mathrm{O}_{4}\right)$. However, it is not unlikely that the interface would be a graded phase, ${ }^{[52]}$ i.e., gradually going from $\mathrm{FeO}$ to $\mathrm{Fe}_{3} \mathrm{O}_{4}$ over a certain thickness. The specific characteristics of this graded interface and the time evolution (which does not necessarily have to be monotonic) would affect the exact results of the $\mathrm{FeO}+\mathrm{Fe}_{3} \mathrm{O}_{4}$-interface model.

Nevertheless, as a whole, the results unambiguously show that the oxidation of the particles goes slightly faster at the beginning and stabilizes for longer times, consistent with the passivation layer role of $\mathrm{Fe}_{3} \mathrm{O}_{4}$ (which may be aided by the formation of antiphase boundaries hindering the oxygen diffusion). However, it is important to highlight that after 4 years the relative volume of the $\mathrm{Fe}_{3} \mathrm{O}_{4}$ counterpart (outer+inner shell) increases from $72.3 \%$ to $83.3 \%$, i.e., implying merely a $\sim 1.3 \mathrm{~nm}$ increase in thickness. 
Further information on the stability of the microstructure can be obtained from the Warren plots of the different phases (Figure 5). The plot displays the dependence of the root mean square displacement (RMSD) versus the distance between two scattering points in the coherent domain. The RMSD is obtained from the root mean square strain (RMSS) using the relation $\mathbf{R M S D}=\mathbf{L} \cdot \mathbf{R M S S}$, where $\mathbf{L}=\mathbf{n} \cdot \boldsymbol{\lambda} / \mathbf{2} \cdot\left(\sin \boldsymbol{\theta}_{\mathbf{2}}-\sin \boldsymbol{\theta}_{1}\right)$ is the Fourier length $\left(\boldsymbol{\theta}_{2}-\boldsymbol{\theta}_{\mathbf{1}}\right.$ is the angular range of the peak profile). ${ }^{[42,53]}$ RMSD was chosen instead of RMSS, since one can follow the strain behavior with $\boldsymbol{L}$. The outer $\mathrm{Fe}_{3} \mathrm{O}_{4}$ shell presents larger RMSD than the other phases. This is expected since it comprises the surface of the nanoparticles, where surface relaxation must be present. However, the strains decrease with time indicating the structure becomes more stable. The inner FeO core has also considerable strains, which are probably related to the topotaxial growth of the $\mathrm{Fe}_{3} \mathrm{O}_{4}$ passivation shell. ${ }^{[17,31]}$ Interestingly, the inner shell and the outer core present relatively low microstrains, which may indicate that the interface phases may have strain relieve mechanism, e.g., stacking faults or graded cell parameters (due to a gradual change in oxygen content).

Finally, to verify possible local structural changes, especially due to the peculiar cubic shape, PDF analysis was applied. First, PDF data from a NIST SRM Si 640d reference sample was modelled up to $500 \AA$ to obtain $\mathrm{Q}_{\text {damp }}$ and $\mathrm{Q}_{\text {broad, }}$ which describe experimental resolution effects. The PDF data modelling resulted in $\mathrm{Q}_{\text {damp }}=0.002857$ and $\mathrm{Q}_{\text {broad }}=$ 0.002897, which were kept fixed during the subsequent fitting procedures. For the PDF data modelling of the samples, cell parameters, isotropic atomic displacement parameters, atomic positions, and the parameter delta2 (which accounts for correlated atomic motion effects in PDFgui ${ }^{[54]}$ ) were refined. The model assumes a $\mathrm{Fe}_{3} \mathrm{O}_{4}$ phase and a $\mathrm{FeO}$ phase only, since PDF cannot differentiate the crystallinities present in the system. Interestingly, when the modelling is performed up to $10 \AA$, no major local distortions are present, since the model promptly converges using only one $\mathrm{Fe}_{3} \mathrm{O}_{4}$ and one $\mathrm{FeO}$ phases (see Figure 6a- 
c). The cell parameters (Table 3) are in accordance with the ones obtained by WPPM. Comparing the evolution of the refined atomic displacement factors, $\mathrm{U}$, for the $\mathrm{Fe}_{3} \mathrm{O}_{4}$ and $\mathrm{FeO}$ phases (Table 3), it can be seen that they remain rather constant (within the experiment error), suggesting that disordering in the phases does not significantly increase with time maintaining the high crystallinity of both structures as the topotaxial transformation takes place (for the NC2014 -NC2017 measurements). Additionally, the phase fractions obtained from PDF (Table 3) agree with the ones determined from Rietveld, confirming that there is an increase in $\mathrm{Fe}_{3} \mathrm{O}_{4}$ content at the expense of $\mathrm{FeO}$. When modelling the PDF up to $25 \AA$, although the simple two-phase model can somewhat reproduce the experimental results (see Figure 6d-f) the fit is worse. This is consistent with the short length of the structural coherence expected for the nanoparticles, which can be attributed to the nanometric particle size and/or structural disorder. ${ }^{[55]}$ These effects cause the decay of the PDF signal and, consequently, the fitting is hampered. Since, correlated atomic motion and instrumental effects were already considered, as stated before, this indicates that strain must be present in the samples. ${ }^{[56]}$ This is consistent with the presence of additional interface phases (and other defects like stacking faults, antiphase boundaries, graded lattice parameters and so on; Figure S3) in the nanoparticles. In particular, the atomic displacement factors for the $25 \AA$ model are larger, indicating that the PDF peaks broaden for increasing $r$, again implying higher disorder for $r=25$ $\AA$. For $r$ larger than $25 \AA$ the two-phase model can no longer describe the experimental data which is consistent with the existence some interface phases, which greatly increase the disorder beyond $r=25 \AA$. Nevertheless, although the data cannot be fit and the intensity of the PDF features decreases with increasing $r$, they remain finite beyond $50 \AA$ (see Figure S4), which indicates that despite the disorder, the structure presents some degree of coherence, as expected for a topotaxial system. 
The magnetic properties of samples NC2013 and NC2017 are shown in Figure 7. In the temperature dependence of the magnetization, $M(T)$, it can be seen that in both cases the nanoparticles are ferromagnetic at room temperature since the ZFC and FC branches do not converge at $350 \mathrm{~K}$. This confirms the presence of a large volume fraction of $\mathrm{Fe}_{3} \mathrm{O}_{4}$ even in the fresh sample (NC2013), in concordance with the XRD analysis. Moreover, the $\mathrm{M}(\mathrm{T})$ of both samples shows a hump at about $230 \mathrm{~K}$, which is associated to the antiferromagnetic transition of $\mathrm{FeO}$, i.e., the Néel temperature, $\mathrm{T}_{\mathrm{N}}$. Note that the $\mathrm{T}_{\mathrm{N}}=230 \mathrm{~K}$ value is slightly higher than the bulk one for $\mathrm{FeO}\left(\mathrm{T}_{\mathrm{N}}(\mathrm{FeO})=\right.$ $200 \mathrm{~K}$ ), which is probably due strain-induced increase of $\mathrm{T}_{\mathrm{N}}^{[57]}$ (owing to the epitaxial strain caused by the growth of the $\mathrm{Fe}_{3} \mathrm{O}_{4}$ shell) or magnetic proximity effects ${ }^{[58]}$ induced by the $\mathrm{Fe}_{3} \mathrm{O}_{4}{ }^{[17]}$

Interestingly, the transition appears less prominent (and with a slightly smaller $\mathrm{T}_{\mathrm{N}}$ ) in sample NC2017, which could tentatively be ascribed to the reduction in FeO volume fraction and the smaller crystallite size of the $\mathrm{FeO}$ inner core observed in NC2017. Note that the reduction of $\mathrm{T}_{\mathrm{N}}$ for smaller sizes is a well-known effect in antiferromagnets. ${ }^{[59,60]}$ At about $\mathrm{T} \sim 125 \mathrm{~K}$ a second transition takes place. This transition corresponds to the Verwey transition, $\mathrm{T}_{\mathrm{V}}$, of $\mathrm{Fe}_{3} \mathrm{O}_{4} .^{[17]}$ The relative importance of the Verwey transition is similar in both samples (NC2013 and NC2017; see Figures 7 and S5), which probably indicates that the volume fraction of wellordered $\mathrm{Fe}_{3} \mathrm{O}_{4}$ (necessary to exhibit $\mathrm{T}_{\mathrm{V}}{ }^{[61]}$ should be similar in both cases. This is somewhat consistent with fast oxidation at the first stages leading to $\mathrm{Fe}_{3} \mathrm{O}_{4}$ shell and the relative stability of the outer $\mathrm{Fe}_{3} \mathrm{O}_{4}$ shell observed in the XRD analysis. In addition, the presence of a stable Verwey transition also implies that no major oxidation to $\gamma$ $\mathrm{Fe}_{2} \mathrm{O}_{3}$ takes place over time.

The low temperature hysteresis loops (Figure 7b) show that the saturation magnetization, $\mathrm{M}_{\mathrm{S}}$, increases from about $10 \mathrm{emu} / \mathrm{g}_{\text {sample }}(\mathrm{NC2013})$ to $25 \mathrm{emu} / \mathrm{g}_{\text {sample }}$ 
(NC2017). The reduced values of $\mathrm{M}_{\mathrm{s}}$ confirm the presence of a non-ferrimagnetic counterpart in the sample, i.e., FeO. Interestingly, the increase in $\mathrm{M}_{\mathrm{S}}$ is larger than the expected from the XRD analysis (which indicates a mere $1.3 \mathrm{~nm}$ increase in the shell thickness). The two results can be reconciled if the outer FeO core also contributed to $\mathrm{M}_{\mathrm{S}}$ in NC2017. Namely, the $\mathrm{Fe}_{0.76} \mathrm{O}$ stoichiometry of the outer FeO core in NC2017 implies a large cation deficiency in the $\mathrm{Fe}_{\mathrm{x}} \mathrm{O}$ structure. This leads to defects which tend to cluster forming in some cases $\mathrm{Fe}_{3} \mathrm{O}_{4}$-like structures. ${ }^{[62]}$ These clusters exhibit a ferrimagnetic signal, ${ }^{[17]}$ which should contribute to the overall $\mathrm{M}_{\mathrm{S}}$. This is consistent with the tendency of the outer $\mathrm{FeO}$ core to eventually become $\mathrm{Fe}_{3} \mathrm{O}_{4}$.

Moreover, the hysteresis loops show a shift in the field axis (i.e., exchange bias, $\mathrm{H}_{\mathrm{E}}$ ). ${ }^{[5]}$ This is a signature of ferro(i)magnetic-antiferromagnetic interface coupling, confirming once again the presence of $\mathrm{Fe}_{3} \mathrm{O}_{4}$ (ferrimagnetic) and $\mathrm{FeO}$ (antiferromagnetic). Interestingly, although the $\mathrm{H}_{\mathrm{E}}$ values of the NC2013 sample are slightly larger than the NC2017 one, they are both rather similar. Since $\mathrm{H}_{\mathrm{E}}$ depends inversely on the thickness of the ferrimagnetic counterpart, ${ }^{[5]}$ this implies that the thickness of the $\mathrm{Fe}_{3} \mathrm{O}_{4}$ contributing to $\mathrm{H}_{\mathrm{E}}$ has not changed much, in agreement with the XRD analysis.

\section{Conclusions}

Summarizing we have shown that a detailed analysis of the synchrotron X-ray diffraction patterns allows gaining information on the interface structure of core/shell nanoparticles averaged over the whole sample. The approach is based on the fact that often at the interface the structural properties may be different than the corresponding constituents. Moreover, we take the advantage that, in contrast to spectroscopic methods, powder diffraction is based on distinctive crystalline phases, making it particularly appealing in systems with two phases comprising the same ion (e.g., different oxidation states or polymorphs). In the particular case 
of the time evolution of $\mathrm{FeO} / \mathrm{Fe}_{3} \mathrm{O}_{4}$ core/shell nanoparticles, the analysis has shown (i) the relative stability of the $\mathrm{Fe}_{3} \mathrm{O}_{4}$ layer, (ii) the progressive oxidation of the $\mathrm{FeO}$ core and (iii) the presence of a significant interface structure formed by $\mathrm{FeO}+\mathrm{Fe}_{3} \mathrm{O}_{4}$ layers different from those of the core or the shell. The structural analysis is consistent with the magnetic properties of the system.

\section{Experimental and methods}

\subsection{Synthesis}

$\mathrm{FeO} / \mathrm{Fe}_{3} \mathrm{O}_{4}$ nanocubes were synthesized following the procedure proposed by Wetterskog et al. ${ }^{[31]}$ with slight modifications. This procedure consists of two steps: 1 ) synthesis of iron (III) oleate and 2) thermal decomposition of iron (III) oleate in eicosane under the presence of oleic acid and sodium oleate. The iron (III) oleate was synthesized according to the procedure reported by Park et al. ${ }^{[63]}$ by refluxing iron (III) chloride and sodium oleate in a mixture of hexane, water and ethanol. In the second step, $11.4 \mathrm{mmol}(10.25 \mathrm{~g})$ of iron (III) oleate, 5.12 mmol (1.44 g) of oleic acid and $5.12 \mathrm{mmol}(1.56 \mathrm{~g})$ of sodium oleate were mixed with $26 \mathrm{~g}$ of eicosane and degassed at room temperature prior to heating up to $70{ }^{\circ} \mathrm{C}$ for $2 \mathrm{~h}$ under $\mathrm{Ar}$ atmosphere to dissolve the sodium oleate. Then, the reaction mixture was heated up to $350{ }^{\circ} \mathrm{C}$ at $3{ }^{\circ} \mathrm{C} \cdot \mathrm{min}^{-1}$ under Ar flow and kept for $30 \mathrm{~min}$. Finally, the reaction was cooled down to room temperature under Ar flow. Purification of the particles was carried out by several cycles of centrifugation with ethanol. Finally, the particles were dispersed in toluene. For Xray powder diffraction and magnetometry, the nanoparticles were prepared in powder form by centrifugation with ethanol followed by drying with Ar flow. The sample was stored in powder form at room temperature in ambient conditions. Note that while the temperature was controlled to some extent (typically between $20-25{ }^{\circ} \mathrm{C}$ ), the humidity was not controlled (which in the Barcelona area fluctuates between about 55\% in summer and 90\% in autumn). 


\subsection{Characterization}

\subsubsection{Transmission Electron Microscopy}

Transmission electron microscopy (TEM) images were collected in a JEM 2011 (JEOL) microscope operating at $200 \mathrm{keV}$. A small amount of particles was suspended in hexane and a few drops were placed on a carbon-coated cupper grid.

\subsubsection{Synchrotron X-ray powder diffraction}

X-ray synchrotron powder diffraction measurements were performed in different dates: September 2013, July 2014, January 2015 and May 2017; namely NC2013, NC2014, NC2015 and NC2017, respectively. Measurements were carried out at the MSPD beamline ${ }^{[64]}$ of the ALBA Synchrotron, using the Mythen II detector. For NC2013 the measurements were performed from $0.003^{\circ}$ up to $47.126^{\circ}$ using $0.006^{\circ}$ with $20 \mathrm{keV}\left(\mathrm{Q}_{\max }=8 \AA^{-1}\right)$. For $\mathrm{NC} 2014$, NC2015 and NC2017, data were taken from $1.041^{\circ}$ up to $124.095^{\circ}, 1.063^{\circ}$ up to $121.093^{\circ}$ and $0.526^{\circ}$ up to $126.298^{\circ}$ using $0.006^{\circ}$ with $30 \mathrm{keV}$, respectively $\left(\mathrm{Q}_{\max }=26.5 \AA^{-1}\right)$. For the instrumental contribution correction, the standard reference material Si 640d from NIST was used for all measurements.

\subsubsection{Whole Powder Pattern Modelling}

The XRD profiles were modelled based on the Whole Powder Pattern Modelling ${ }^{[42]}$ to access the long-range ordered structure. With WPPM it is possible to represent the background and peak shapes by refining parameters for instrumental, geometrical and microstructural effects in the XRD data. The fitting procedure was performed by means of the $P M 2 K v .3$ software ${ }^{[65]}$. The refined parameters were the mean crystallite size, the size distribution and the microstrain. For the size analysis, spherical and cubic domains were tested to model the profiles. The best result was obtained when spherical shaped domains were used (in concordance with the TEM analysis; see Figure S6 and Supporting Information). This implies that the layers which form the nanocubes are composed by small spheres stacked together (as will be discussed later). The strain analysis was performed using the model proposed by 
Scardi and Leonardi, ${ }^{[42,53]}$ where strain anisotropy can be accounted according to the symmetry of the elastic tensor ${ }^{[42]}$. The model permits calculating the Warren plot ${ }^{[66]}$, which allows the local atomic displacement to be represented. The Warren plot gives the root mean square displacement (RMSD) vs $\boldsymbol{L}$, where $\boldsymbol{L} \boldsymbol{L}$ is the distance between two scattering points inside the coherent domain ${ }^{[53]}$.

Note that WPPM is particularly suited to deal with asymmetric peaks as the ones displayed by nanometric non-spherical structures.

\subsubsection{Rietveld refinement}

Rietveld refinement was applied to the XRD data using the TOPAS v.6 software. The refined parameters were the scale factor, zero-error, background coefficients, lattice parameters using $\mathrm{Fe}_{3} \mathrm{O}_{4}$ (ICSD No. 75627) and FeO (ICSD No. 633029) CIF files as starting models. Since the experimental data were collected in transmission geometry absorption correction was applied. This is mainly caused by the heavy convolution between the peaks.

\subsubsection{Pair distribution function $(P D F)$}

PDF analysis was applied for the NC2014, NC2015 and NC2017 XRD data. The PDF function $\boldsymbol{G}(\boldsymbol{r}) \boldsymbol{G}(\boldsymbol{r})$ (where $r$ is the radial distance between two atoms inside the coherent domain) can be obtained by a Fourier Transform of the total scattering intensity $S(Q) S(Q)^{[67]}$ :

$$
G(r)=\frac{2}{\pi} \int_{0}^{\infty} Q[S(Q)-1] \sin (Q r) d Q
$$

where $\boldsymbol{Q}$ is the magnitude of the scattering vector. With $\boldsymbol{G}(\boldsymbol{r})$ it is possible to determine the relative position of the atoms in any solid ${ }^{[67]}$ which makes PDF analysis extremely useful to handle systems with poor crystalline periodicity such as nanoparticles. $\boldsymbol{G}(\boldsymbol{r})$ was obtained using the $P D F g e t X 3^{[54]}$ software and modelled using PDFgui $1.1^{[68]}$ either up to $10 \AA$ or $25 \AA$. The refined parameters were the scale factor, cell parameters, atomic displacement factors and delta2 (which accounts for correlated atomic motion effects). The instrumental parameters 
$\boldsymbol{Q}_{\text {broad }}$ and $\boldsymbol{Q}_{\text {damp }}$ were obtained by refining NIST SRM Si 640d PDF data up to $500 \AA$ A. Note that PDF was applied only to the data from 2014 onwards, since in 2013 the energy used was $20 \mathrm{keV}$, with a reduced $2 \theta$ range (up to $47.126^{\circ}$ ), providing a $\mathrm{Q}_{\max }$ of $8 \AA^{-1}$, which does not allow the correct application of PDF.

\subsubsection{Magnetometry}

Magnetic properties were evaluated using a SQUID magnetometer (MPMS-XL, Quantum Design). The dried nanoparticles were tightly packed in Teflon tape. The measurements of the temperature dependence of magnetization, $\mathrm{M}(\mathrm{T})$, were carried out at 25 Oe after either zero field cooling (ZFC) or field cooling (FC) conditions. Hysteresis loops, $\mathrm{M}(\mathrm{H})$, were obtained at $10 \mathrm{~K}$ after $\mathrm{FC}$ in $70 \mathrm{kOe}$ from room temperature.

\section{Supporting Information}

Low magnification TEM image evidencing the homogeneity of the smaple. WPPM fitting at the $2.5 \AA^{-1}$ region to show the improved fit with 4 phases. HR-TEM image of one nanoparticle highlighting the formation of defects and analysis of the formation of crystallites by filtered inverse-FFT of HR-TEM images. Supporting Information is available from the Wiley Online Library or from the author.

\section{Acknowledgements}

RUI acknowledges CAPES and CNPq (No. 206983/2014-0) Brazilian agencies. AGR and JN thank the support of the Generalitat de Catalunya through the 2017-SGR-292 project and the Beatriu de Pinos Program (2011 BPB 00209) and the Spanish Ministerio de Economía y Competitividad (MINECO) through the MAT2016-77391-R project. I. Peral is supported by the National Research Fund of Luxembourg (Grant No FNR-Inter2015/LRSF). ALO acknowledges the MINECO through the Juan de la Cierva Program (IJCI-2014-21530). XT would like to acknowledge the financial support from the MINECO projects MAT201567593-P and BIA2014-57658-C2-1-R. The ALBA Synchrotron is acknowledged for the provision of beamtime and the MSPD beamline staff is for their help during the XRD measurements. Prof. Dr. Luis G. Martinez from IPEN/CNEN is acknowledged for useful discussions about XRD techniques. Prof. Dr. Paolo Scardi from Università degli Studi di Trento is acknowledged for the helpful discussions about WPPM and for providing PM2Kv.3 software. ICN2 is funded by the CERCA Programme/Generalitat de Catalunya. ICN2 also acknowledges support from the Severo Ochoa Program (MINECO, grant SEV-2013-0295). 
References

[1] D. V. Talapin, J.-S. Lee, M. V. Kovalenko, E. V. Shevchenko, Chem. Rev. 2010, 110, 389.

[2] L. Carbone, P. D. Cozzoli, Nano Today 2010, 5, 449.

[3] C. de M. Donega, Chem. Soc. Rev. 2011, 40, 1512.

[4] A. Lopez-Ortega, M. Estrader, G. Salazar-Alvarez, A. G. Roca, J. Nogues, Phys. Rep. $\mathbf{2 0 1 5}, 553,1$.

[5] J. Nogués, J. Sort, V. Langlais, V. Skumryev, S. Suriñach, J. S. Muñoz, M. D. Baró, Phys. Rep. 2005, 422, 65.

[6] P. Li, Z. Wei, T. Wu, Q. Peng, Y. Li, J. Am. Chem. Soc. 2011, 133, 5660.

[7] X. Yu, A. Shavel, X. An, Z. Luo, M. Ibañez, A. Cabot, J. Am. Chem. Soc. 2014, 136, 9236.

[8] A. Juhin, A. López-Ortega, M. Sikora, C. Carvallo, M. Estrader, S. Estradé, F. Peiró, M. D. Baró, P. Sainctavit, P. Glatzel, J. Nogués, Nanoscale 2014, 6, 11911.

[9] M. Saruyama, M. Kanehara, T. Teranishi, Chem. Commun. 2009, 2724.

[10] G. D. Moon, S. Ko, Y. Min, J. Zeng, Y. Xia, U. Jeong, Nano Today 2011, 6, 186.

[11] E. Skoropata, T. T. Su, H. Ouyang, J. W. Freeland, J. van Lierop, Phys. Rev. B 2017, $96,024447$.

[12] M. Varela, J. Gazquez, S. J. Pennycook, MRS Bull. 2012, 37, 29.

[13] S. Estradé, L. Yedra, A. López-Ortega, M. Estrader, G. Salazar-Alvarez, M. D. Baró, J. Nogués, F. Peiró, Micron 2012, 43, 30.

[14] P. Torruella, R. Arenal, F. de la Peña, Z. Saghi, L. Yedra, A. Eljarrat, L. López-Conesa, M. Estrader, A. López-Ortega, G. Salazar-Alvarez, J. Nogués, C. Ducati, P. A. Midgley, F. Peiró, S. Estradé, Nano Lett. 2016, 16, 5068.

[15] K. L. Krycka, J. A. Borchers, G. Salazar-Alvarez, A. López-Ortega, M. Estrader, S. Estradé, E. Winkler, R. D. Zysler, J. Sort, F. Peiró, B. M. Dolors, C.-C. Kao, J. Nogués, 
ACS Nano 2013, 7, 921.

[16] T. Gaudisson, R. Sayed-Hassan, N. Yaacoub, G. Franceschin, S. Nowak, J.-M.

Grenéche, N. Menguy, P. Sainctavit, S. Ammar, CrystEngComm 2016, 18, 3799.

[17] M. Estrader, A. López-Ortega, I. V. Golosovsky, S. Estradé, A. G. Roca, G. SalazarAlvarez, L. López-Conesa, D. Tobia, E. Winkler, J. D. Ardisson, W. A. A. Macedo, A. Morphis, M. Vasilakaki, K. N. Trohidou, A. Gukasov, I. Mirebeau, O. L. Makarova, R. D. Zysler, F. Peiró, M. D. Baró, L. Bergström, J. Nogués, Nanoscale 2015, 7, 3002.

[18] M. Popovici, M. Gich, D. Niznansky, A. Roig, C. Savii, L. Casas, E. Molins, K. Zaveta, C. Enache, J. Sort, S. de Brion, G. Chouteau, J. Nogues, Chem. Mater. 2004, $16,5542$.

[19] C. Piquer, M. A. Laguna-Marco, A. G. Roca, R. Boada, C. Guglieri, J. Chaboy, J. Phys. Chem. C 2014, 118, 1332.

[20] T. J. Regan, H. Ohldag, C. Stamm, F. Nolting, J. Lüning, J. Stöhr, R. L. White, Phys. Rev. B 2001, 64, 214422.

[21] D. W. Kavich, J. H. Dickerson, S. V. Mahajan, S. A. Hasan, J.-H. Park, Phys. Rev. B 2008, 78, 174414.

[22] A. Lak, J. Dieckhoff, F. Ludwig, J. M. Scholtyssek, O. Goldmann, H. Lünsdorf, D. Eberbeck, A. Kornowski, M. Kraken, F. J. Litterst, K. Fiege, P. Mischnick, M. Schilling, Nanoscale 2013, 5, 11447.

[23] A. Stamatiou, P. G. Loutzenhiser, A. Steinfeld, Chem. Mater. 2010, 22, 851.

[24] L. Xiao, S.-Y. Wu, Y.-R. Li, Renew. Energy 2012, 41, 1.

[25] L. Shi, Y. D. He, X. H. Xia, Z. M. Jian, H. B. Liu, J. Iran. Chem. Soc. 2010, 7, 721.

[26] J. Zheng, Z. Yu, G. Ji, X. Lin, H. Lv, Y. Du, J. Alloys Compd. 2014, 602, 8.

[27] H. Khurshid, J. Alonso, Z. Nemati, M. H. Phan, P. Mukherjee, M. L. Fdez-Gubieda, J. M. Barandiarán, H. Srikanth, J. Appl. Phys. 2015, 117, 17A337.

[28] M. V. Kovalenko, M. I. Bodnarchuk, R. T. Lechner, G. Hesser, F. Schäffler, W. Heiss, 
J. Am. Chem. Soc. 2007, 129, 6352.

[29] A. Navrotsky, L. Mazeina, J. Majzlan, Science 2008, 319, 1635.

[30] B. P. Pichon, O. Gerber, C. Lefevre, I. Florea, S. Fleutot, W. Baaziz, M. Pauly, M. Ohlmann, C. Ulhaq, O. Ersen, V. Pierron-Bohnes, P. Panissod, M. Drillon, S. BeginColin, Chem. Mater. 2011, 23, 2886.

[31] E. Wetterskog, C.-W. Tai, J. Grins, L. Bergström, G. Salazar-Alvarez, ACS Nano 2013, $7,7132$.

[32] A. Corrias, G. Mountjoy, D. Loche, V. Puntes, A. Falqui, M. Zanella, W. J. Parak, M. F. Casula, J. Phys. Chem. C 2009, 113, 18667.

[33] C.-J. Chen, R.-K. Chiang, H.-Y. Lai, C.-R. Lin, J. Phys. Chem. C 2010, 114, 4258.

[34] M. J. Benitez, D. Mishra, P. Szary, G. A. Badini Confalonieri, M. Feyen, A. H. Lu, L. Agudo, G. Eggeler, O. Petracic, H. Zabel, J. Phys. Condens. Matter 2011, 23, 126003.

[35] G. Salazar-Álvarez, J. Sort, S. Suriñach, M. D. Baró, J. Nogués, J. Am. Chem. Soc. 2007, 129, 9102 .

[36] A. López-Ortega, D. Tobia, E. Winkler, I. V. Golosovsky, G. Salazar-Alvarez, S. Estradé, M. Estrader, J. Sort, M. A. González, S. Suriñach, J. Arbiol, F. Peiró, R. D. Zysler, M. D. Baró, J. Nogués, J. Am. Chem. Soc. 2010, 132, 9398.

[37] E. Lottini, A. López-Ortega, G. Bertoni, S. Turner, M. Meledina, G. Van Tendeloo, C. de Julián Fernández, C. Sangregorio, Chem. Mater. 2016, 28, 4214.

[38] A. López-Ortega, E. Lottini, G. Bertoni, C. de Julián Fernández, C. Sangregorio, Chem. Mater. 2017, 29, 1279.

[39] R. Chalasani, S. Vasudevan, J. Phys. Chem. C 2011, 115, 18088.

[40] K. Koga, D. Zubia, J. Phys. Chem. C 2008, 112, 2079.

[41] M. Figlarz, Solid State Ionics 1990, 43, 143.

[42] P. Scardi, A. Leonardi, L. Gelisio, M. R. Suchomel, B. T. Sneed, M. K. Sheehan, C.-K. Tsung, Phys. Rev. B 2015, 91, 155414. 
[43] K. Beyerlein, A. Cervellino, M. Leoni, R. L. Snyder, P. Scardi, Zeitschrift für Krist. Suppl. 2009, 30, 85.

[44] F. Bertolotti, D. Moscheni, A. Migliori, S. Zacchini, A. Cervellino, A. Guagliardi, N. Masciocchi, Acta Crystallogr. Sect. A Found. Adv. 2016, 72, 632.

[45] I. V. Golosovsky, I. Mirebeau, F. Fauth, M. Mazaj, D. A. Kurdyukov, Y. A. Kumzerov, Phys. Rev. B 2006, 74, 155440.

[46] T. Ungár, J. Gubicza, G. Ribárik, A. Borbély, J. Appl. Crystallogr. 2001, 34, 298.

[47] T. Ungár, Scr. Mater. 2004, 51, 777.

[48] A. Lak, D. Niculaes, G. C. Anyfantis, G. Bertoni, M. J. Barthel, S. Marras, M. Cassani, S. Nitti, A. Athanassiou, C. Giannini, T. Pellegrino, Sci. Rep. 2016, 6, 33295.

[49] C. A. McCammon, L. Liu, Phys. Chem. Miner. 1984, 10, 106.

[50] J. A. De Toro, M. Vasilakaki, S. S. Lee, M. S. Andersson, P. S. Normile, N. Yaacoub, P. Murray, E. H. Sánchez, P. Muñiz, D. Peddis, R. Mathieu, K. Liu, J. Geshev, K. N. Trohidou, J. Nogués, Chem. Mater. 2017, 29, 8258.

[51] A. Cervellino, R. Frison, G. Cernuto, A. Guagliardi, N. Masciocchi, J. Appl. Crystallogr. 2014, 47, 1755.

[52] A. López-Ortega, M. Estrader, G. Salazar-Alvarez, S. Estradé, I. V. Golosovsky, R. K. Dumas, D. J. Keavney, M. Vasilakaki, K. N. Trohidou, J. Sort, F. Peiró, S. Suriñach, M. D. Baró, J. Nogués, Nanoscale 2012, 4, 5138.

[53] A. Leonardi, P. Scardi, Metall. Mater. Trans. A 2016, 47, 5722.

[54] C. L. Farrow, P. Juhas, J. W. Liu, D. Bryndin, E. S. Božin, J. Bloch, T. Proffen, S. J. L. Billinge, J. Phys. Condens. Matter 2007, 19, 335219.

[55] A. H. Hill, M. Allieta, Phys. Chem. Chem. Phys. 2013, 15, 8583.

[56] A. S. Masadeh, E. S. Božin, C. L. Farrow, G. Paglia, P. Juhas, S. J. L. Billinge, A. Karkamkar, M. G. Kanatzidis, Phys. Rev. B 2007, 76, 115413.

[57] I. Kantor, L. Dubrovinsky, C. Mccammon, N. Dubrovinskaia, I. Goncharenko, A. 
Kantor, A. Kuznetsov, W. Crichton, Phase Transitions 2007, 80, 1151.

[58] I. V. Golosovsky, G. Salazar-Alvarez, A. López-Ortega, M. A. González, J. Sort, M. Estrader, S. Suriñach, M. D. Baró, J. Nogués, Phys. Rev. Lett. 2009, 102, 247201.

[59] X. G. Zheng, C. N. Xu, K. Nishikubo, K. Nishiyama, W. Higemoto, W. J. Moon, E. Tanaka, E. S. Otabe, Phys. Rev. B 2005, 72, 014464.

[60] S. Sako, K. Ohsima, M. Sakai, S. Bandow, Surf. Rev. Lett. 1996, 03, 109.

[61] F. Walz, J. Phys. Condens. Matter 2002, 14, R285.

[62] C. R. A. Catlow, B. E. F. Fender, J. Phys. C Solid State Phys. 1975, 8, 3267.

[63] J. Park, K. An, Y. Hwang, J.-G. Park, H.-J. Noh, J.-Y. Kim, J.-H. Park, N.-M. Hwang, T. Hyeon, Nat. Mater. 2004, 3, 891.

[64] F. Fauth, I. Peral, C. Popescu, M. Knapp, Powder Diffr. 2013, 28, S360.

[65] P. Scardi, in Powder Diffr., Royal Society Of Chemistry, Cambridge, 2008, pp. 376413.

[66] B. E. Warren, B. L. Averbach, J. Appl. Phys. 1950, 21, 595.

[67] T. Egami, S. J. L. Billinge, Underneath the Bragg Peaks, Structural Analysis of Complex Materials, Elsevier, Amsterdam, The Netherlands, 2003.

[68] P. Juhás, T. Davis, C. L. Farrow, S. J. L. Billinge, J. Appl. Crystallogr. 2013, 46, 560. 


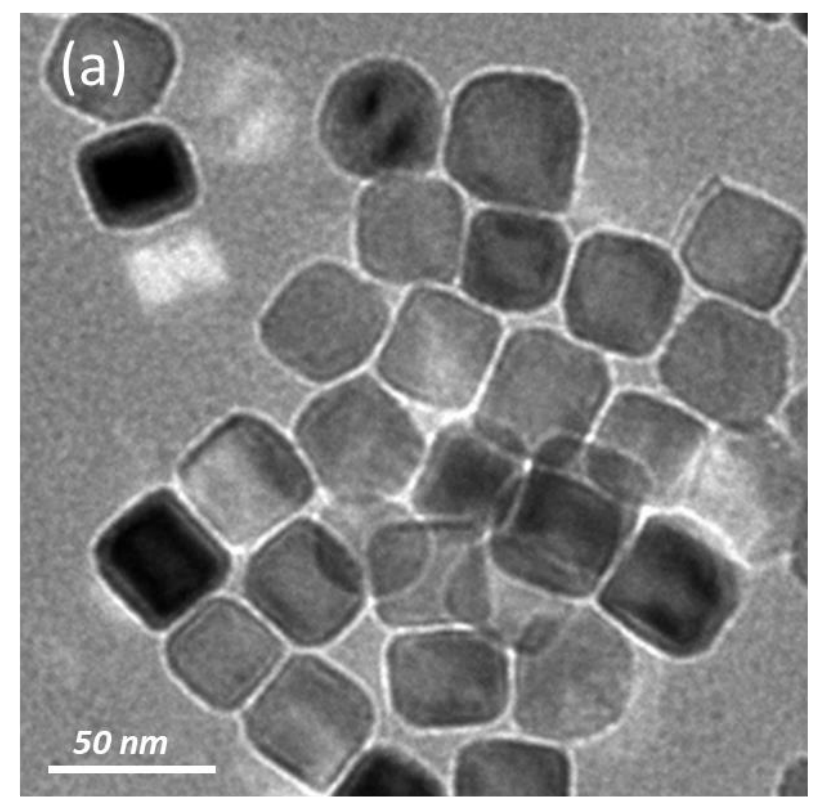

(b)
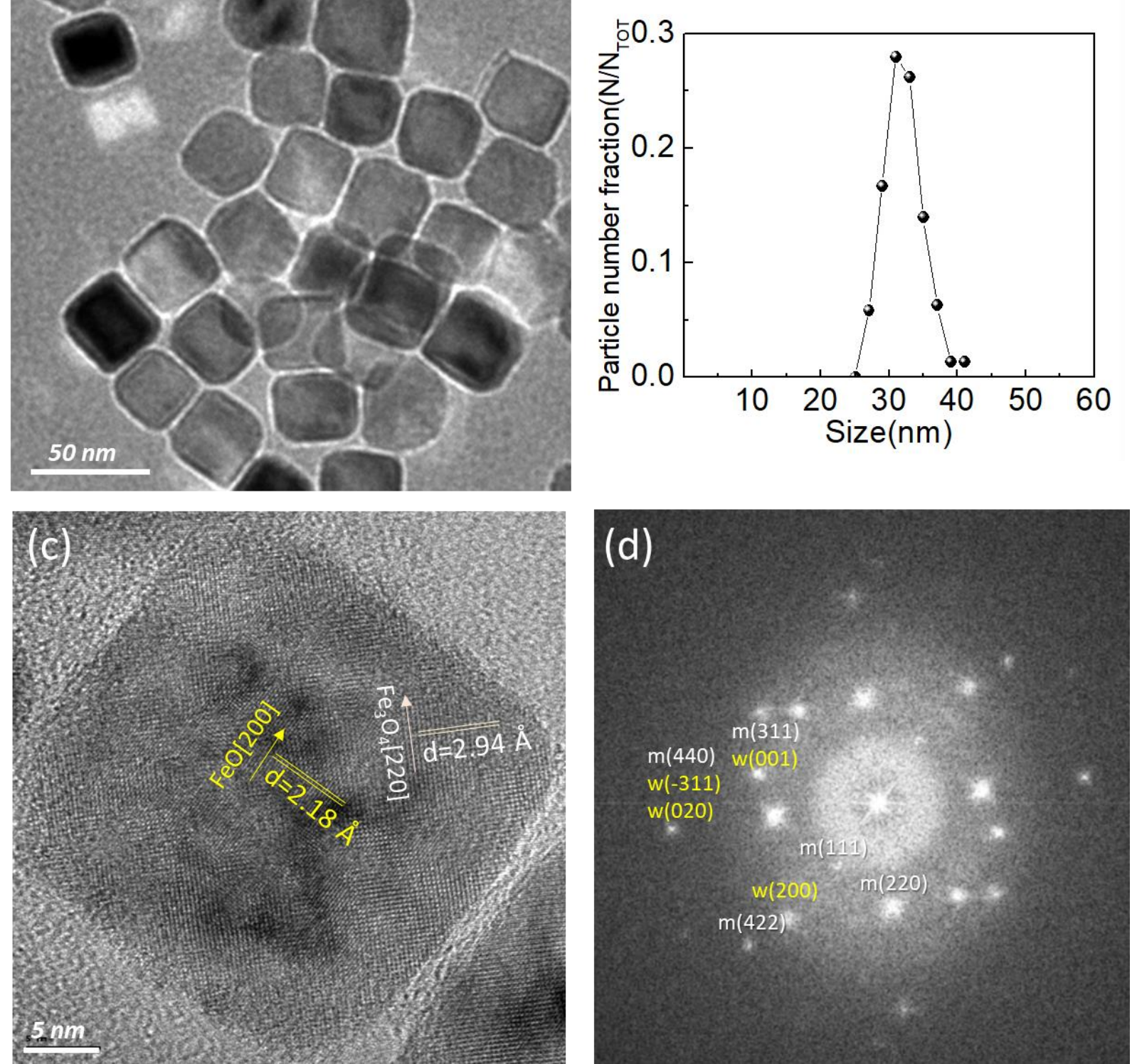

Figure 1. (a) TEM image of the iron oxide nanocubes; (b) Particle size distribution and its fit to a log-normal distribution function; (c) HR-TEM image of one particle and (d) its corresponding Fast Fourier Transform, where the main spots have been indexed to either $\mathrm{FeO}$ (w) or $\mathrm{Fe}_{3} \mathrm{O}_{4}(\mathrm{~m})$. 


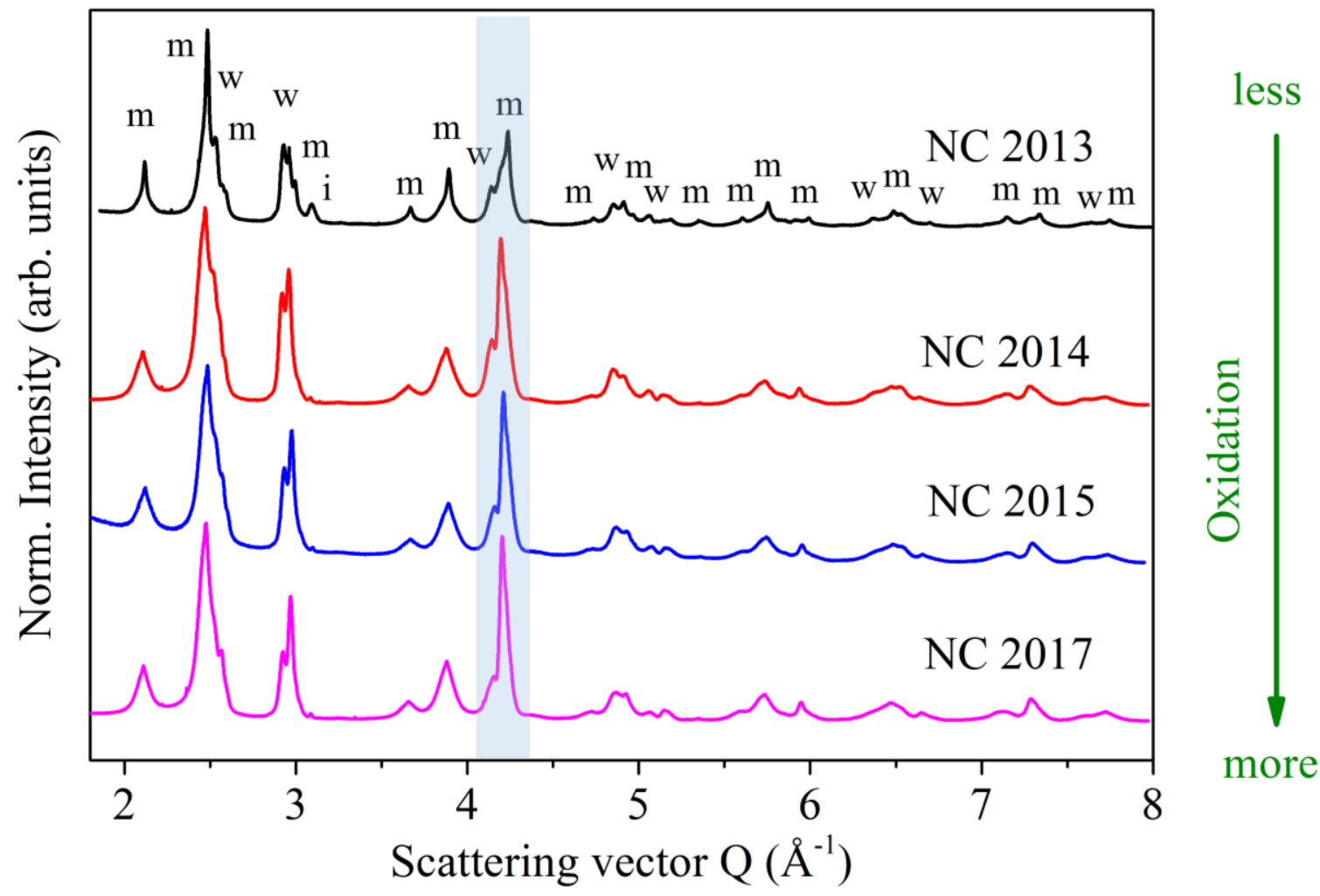

Figure 2. Synchrotron XRD patters for samples NC2013, NC2014, NC2015 and NC2017.The indexes stand for: $\mathrm{m}-\mathrm{Fe}_{3} \mathrm{O}_{4}, \mathrm{w}-\mathrm{FeO}$ and $\mathrm{i}-\alpha$-Iron. 

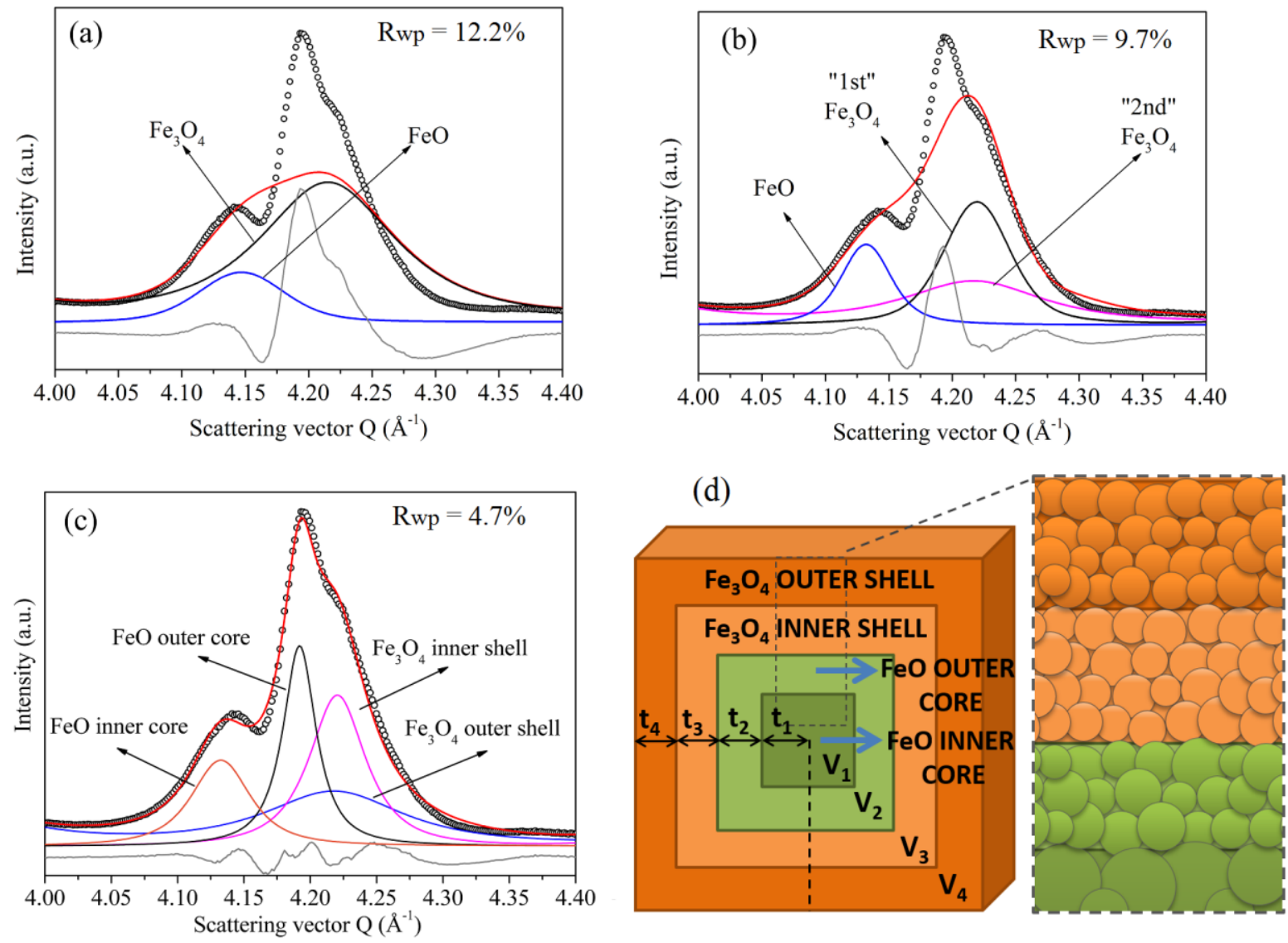

Figure 3. WPPM fitting at the $4.2 \AA^{-1}$ region that presents a superposition of the [lllll $\left.4 \begin{array}{ll}4 & 2\end{array}\right]$ $\mathrm{Fe}_{3} \mathrm{O}_{4}$ and $\left[\begin{array}{lll}0 & 2 & 2\end{array}\right] \mathrm{FeO}$ diffraction peaks using either (a) two phases $\left(\mathrm{Fe}_{3} \mathrm{O}_{4}+\mathrm{FeO}\right)$, (b) three phases $\left(1^{\text {st }} \mathrm{Fe}_{3} \mathrm{O}_{4}\right.$ phase $+\mathrm{FeO}+2^{\text {nd }} \mathrm{Fe}_{3} \mathrm{O}_{4}$ phase $)$ (c) four phases $\left(\mathrm{Fe}_{3} \mathrm{O}_{4}\right.$-outer shell/ $\mathrm{Fe}_{3} \mathrm{O}_{4}$ inner shell/FeO-outer core/FeO-inner core). Black dots: experimental data, red line: fitted profile, grey line: difference between experimental and calculated. (d) Schematic representation the four phases of the nanoparticle and their microstructure. 

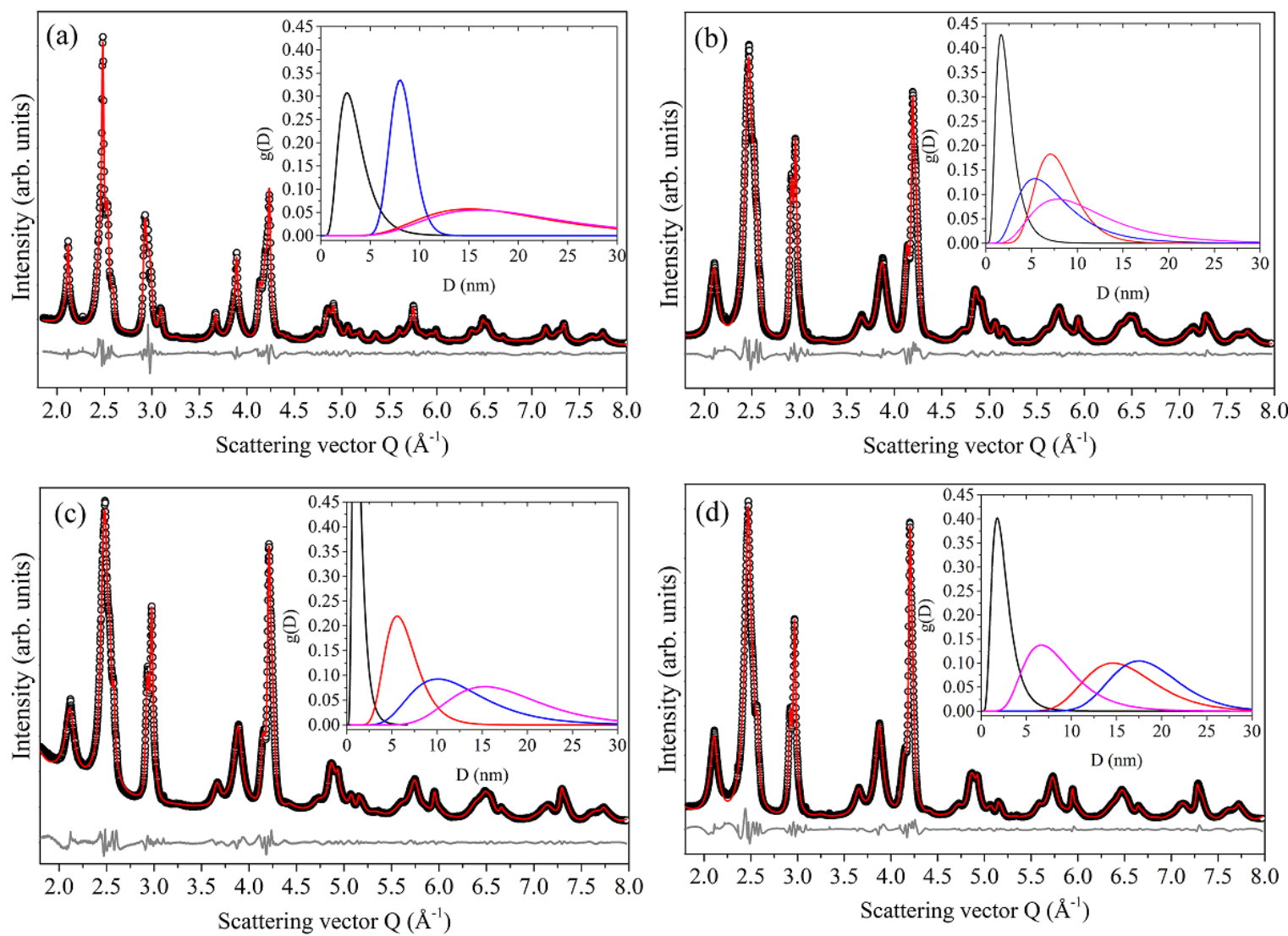

Figure 4. WPPM analysis using X-ray synchrotron diffraction data based on $2 \mathrm{Fe}_{3} \mathrm{O}_{4}$ and 2 FeO phases for (a) NC 2013, (b) NC 2014, (c) NC 2015 and (d) NC 2017; Black dots: experimental data, red line: calculate profile, grey line: difference between experimental and calculated. In the inset the crystallite size distribution [particle number fraction $\left.\left(\mathrm{N} / \mathrm{N}_{\mathrm{Tot}}\right), \mathrm{g}(\mathrm{D})\right]$ is presented for each calculated profile: Black line: $\mathrm{Fe}_{3} \mathrm{O}_{4}$ outer shell, red line: $\mathrm{Fe}_{3} \mathrm{O}_{4}$ inner shell, blue line: $\mathrm{FeO}$ outer core and pink line: $\mathrm{FeO}$ inner core. 

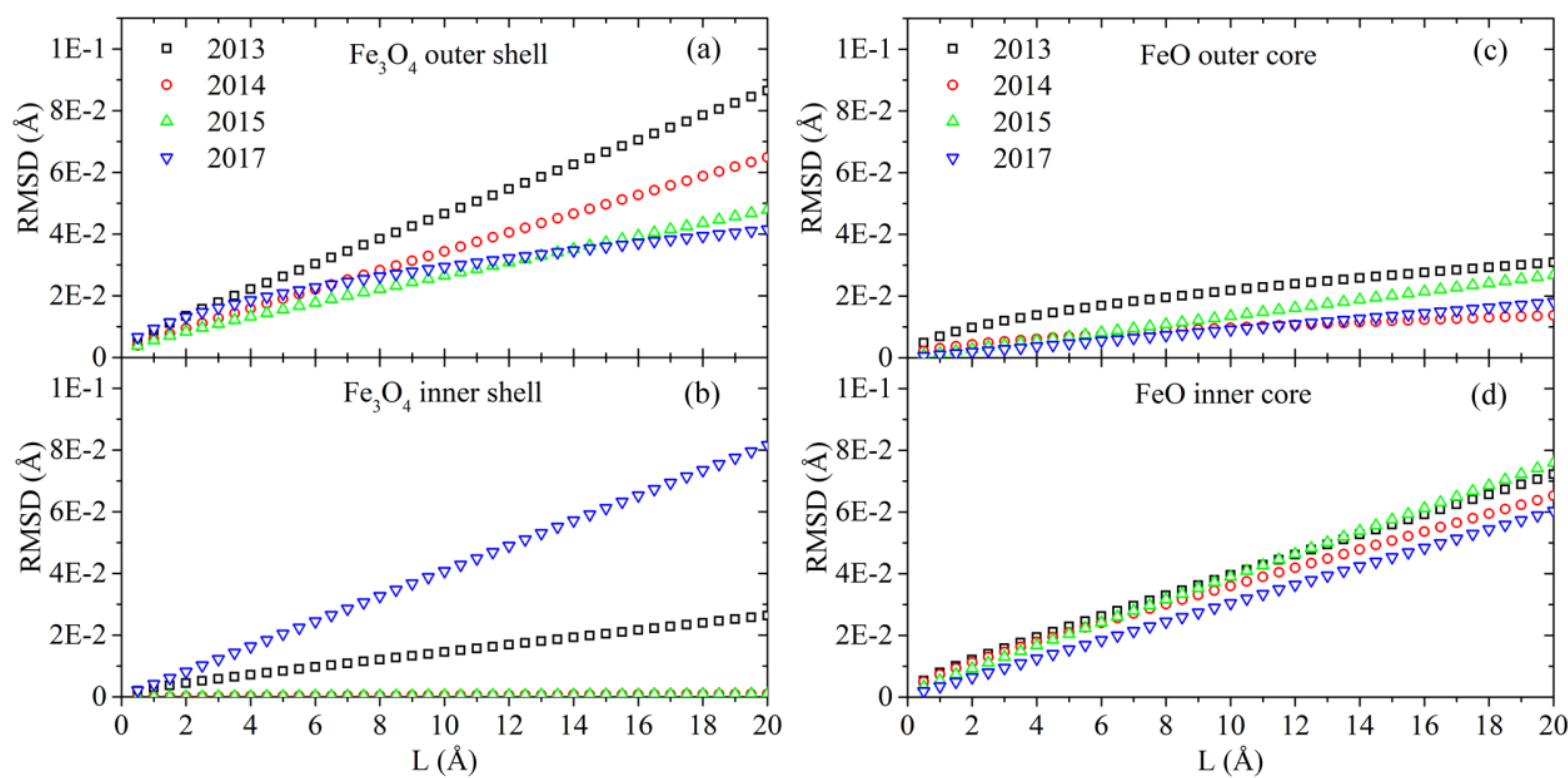

Figure 5. Warren plots, i.e., root-mean-square deviation of atomic positions (RMSD) as a function of the distance between two scattering points within the scattering domains (L), for the diverse phases: (a) $\mathrm{Fe}_{3} \mathrm{O}_{4}$ Outer shell, (b) $\mathrm{Fe}_{3} \mathrm{O}_{4}$ inner shell, (c) $\mathrm{FeO}$ outer Core, and (d) FeO inner core. 


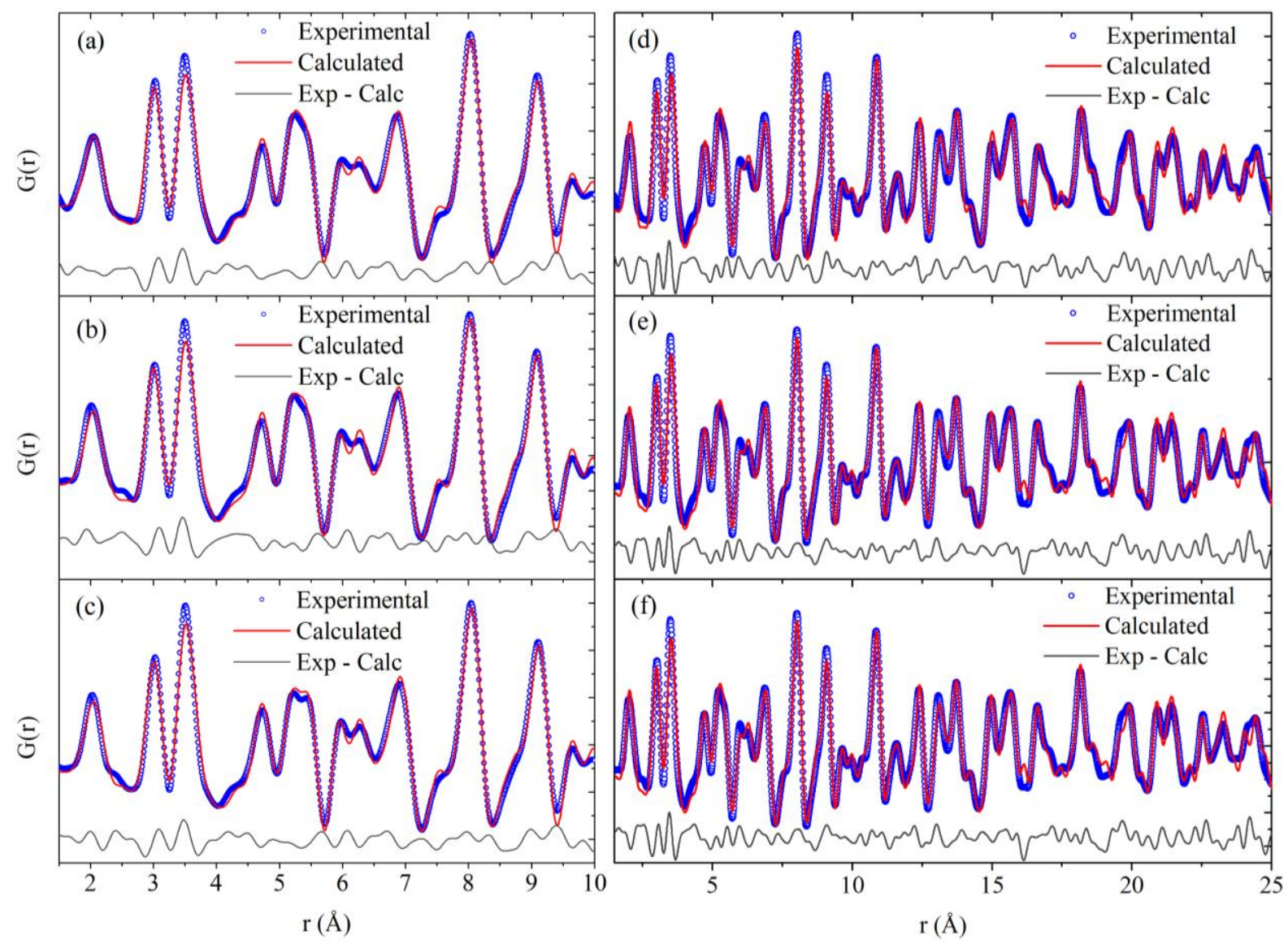

Figure 6. X-ray PDF data modeling, i.e., dependence of PDF function $G$ on the radial distance r, for the (a) NC2014, (b) NC2015 and (c) NC2017 samples up to $10 \AA$ and (d) NC2014, (e) NC2015 and (f) NC2017 samples up to $25 \AA$. 

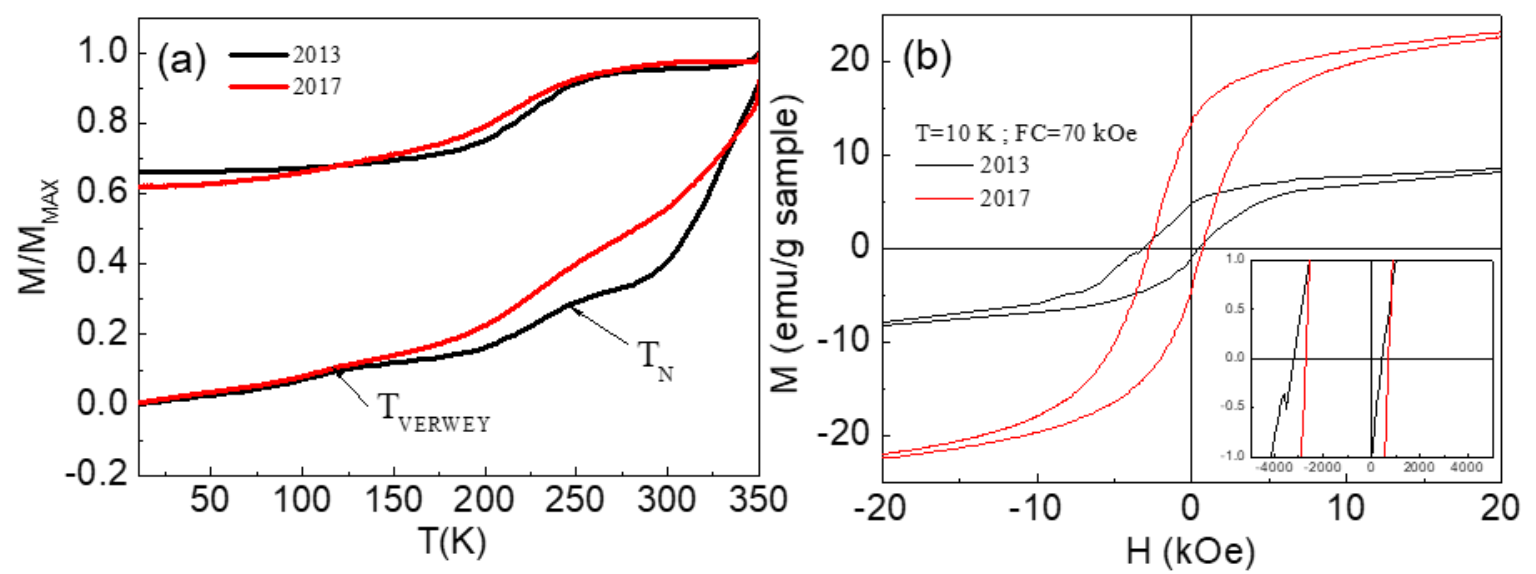

Figure 7. (a) Temperature dependence of the field cooled (FC) and zero field cooled (ZFC) normalized magnetizations [with respect to $\mathrm{M}_{\mathrm{FC}}(\mathrm{T}=350 \mathrm{~K})$ ] for $\mathrm{NC} 2013$ $\left[\mathrm{M}_{\mathrm{FC}}(\mathrm{T}=350 \mathrm{~K})=3.95 \mathrm{emu} / \mathrm{g}\right]$ and $\mathrm{NC} 2017\left[\mathrm{M}_{\mathrm{FC}}(\mathrm{T}=350 \mathrm{~K})=5.32 \mathrm{emu} / \mathrm{g}\right] ;(\mathrm{b})$ Medium field part of the hysteresis loops of the NC2013 and NC2017 samples measured at $10 \mathrm{~K}$ up to $70 \mathrm{kOe}$ after cooling under a field of $70 \mathrm{kOe}$. Shown in the inset are the enlarged hysteresis loops at low fields. 
Table 1. WPPM refined values for cell parameter (a), mean crystallite size (D), size distribution standard deviation $(\sigma)$ and iron content $(x)$ for the $\mathrm{Fe}_{\mathrm{x}} \mathrm{O}$ phase. The letters after the phase name stands for: OS - outer shell, IS - inner shell, OC - outer core and IC - inner core.

\begin{tabular}{lllll}
\hline $\mathrm{Fe}_{3} \mathrm{O}_{4} \mathrm{OS}$ & 2013 & 2014 & 2015 & 2017 \\
\hline $\mathrm{a}(\mathrm{nm})^{*}$ & $0.83950(6)$ & $0.83950(8)$ & $0.83950(7)$ & $0.83950(5)$ \\
$\mathrm{D}(\mathrm{nm})$ & $3.6(1)$ & $2.4(1)$ & $1.3(1)$ & $2.6(1)$ \\
$\sigma(\mathrm{nm})$ & $1.7(1)$ & $1.3(1)$ & $0.7(2)$ & $1.4(1)$ \\
\hline $\mathrm{Fe}_{3} \mathrm{O}_{4} \mathrm{IS}$ & 2013 & 2014 & 2015 & 2017 \\
\hline $\mathrm{a}(\mathrm{nm})^{*}$ & $0.83910(8)$ & $0.83910(8)$ & $0.83910(9)$ & $0.83910(8)$ \\
$\mathrm{D}(\mathrm{nm})$ & $19.7(3)$ & $8.1(2)$ & $6.4(2)$ & $16.2(9)$ \\
$\sigma(\mathrm{nm})$ & $8.7(4)$ & $2.4(4)$ & $2.0(5)$ & $4.3(9)$ \\
\hline $\mathrm{FeO} \mathrm{OC}$ & 2013 & 2014 & 2015 & 2017 \\
\hline $\mathrm{a}(\mathrm{nm})$ & $0.42318(8)$ & $0.42254(3)$ & $0.42192(6)$ & $0.42174(1)$ \\
$\mathrm{D}(\mathrm{nm})$ & $8.3(9)$ & $7.8(2)$ & $12.7(8)$ & $18.7(6)$ \\
$\sigma(\mathrm{nm})$ & $1.2(1)$ & $4.1(2)$ & $5.2(4)$ & $4.0(1)$ \\
$\mathrm{x}$ & 0.79 & 0.77 & 0.76 & 0.76 \\
\hline $\mathrm{FeO} \mathrm{IC}$ & 2013 & 2014 & 2015 & 2017 \\
\hline $\mathrm{a}(\mathrm{nm})$ & $0.42946(6)$ & $0.42860(5)$ & $0.42829(8)$ & $0.42814(1)$ \\
$\mathrm{D}(\mathrm{nm})$ & $20.6(2)$ & $11.4(1)$ & $17.8(6)$ & $8.5(3)$ \\
$\sigma(\mathrm{nm})$ & $9.0(1)$ & $6.0(6)$ & $5.9(2)$ & $3.5(1)$ \\
$\mathrm{x}$ & 0.92 & 0.90 & 0.89 & 0.89 \\
\hline
\end{tabular}

Table 2. Relative volume (V) determined from Rietveld and calculated thickness (t) assuming a cubic nanoparticle with $32 \mathrm{~nm}$ edge length. The letters after the phase name stand for: OS outer shell, IS - inner shell, OC - outer core and IC - inner core.

\begin{tabular}{cccccc}
\hline & & $\mathrm{Fe}_{3} \mathrm{O}_{4} \mathrm{OS}$ & $\mathrm{Fe}_{3} \mathrm{O}_{4} \mathbf{I S}$ & $\mathbf{F e O ~ O C}$ & $\mathbf{F e O ~ I C}$ \\
\hline \multirow{2}{*}{2013} & $\mathbf{V ( \% )}$ & $57.4(2)$ & $14.9(1)$ & $8.1(3)$ & $16.8(3)$ \\
\cline { 2 - 6 } & $\mathbf{t}(\mathbf{n m})$ & 4.1 & 1.7 & 1.3 & 8.9 \\
\hline \multirow{2}{*}{2014} & $\mathbf{V ( \% )}$ & $50.8(2)$ & $28.5(3)$ & $7.8(1)$ & $12.9(2)$ \\
\cline { 2 - 6 } & $\mathbf{t}(\mathbf{n m})$ & 3.2 & 3.2 & 1.4 & 8.2 \\
\hline \multirow{2}{*}{2015} & $\mathbf{V ( \% )}$ & $50.2(1)$ & $32.8(3)$ & $8.1(2)$ & $8.9(3)$ \\
\cline { 2 - 6 } & $\mathbf{t}(\mathbf{n m})$ & 3.2 & 3.9 & 1.7 & 7.2 \\
\hline \multirow{2}{*}{2017} & $\mathbf{V ( \% )}$ & $51.2(3)$ & $32.1(1)$ & $8.0(2)$ & $8.7(1)$ \\
\cline { 2 - 6 } & $\mathbf{t}(\mathbf{n m})$ & 3.3 & 3.8 & 1.7 & 7.2 \\
\hline
\end{tabular}


Table 3. Cell parameters (a) in nm, atomic displacement factors (U) in $\AA 2$ and $\mathrm{FeO} / \mathrm{Fe}_{3} \mathrm{O}_{4}$ weight in percent determined from PDF data refined up to either $10 \AA$ or $25 \AA$.

\begin{tabular}{|c|c|c|c|}
\hline $\begin{array}{l}\text { Refined } \\
\text { up to } 10 \AA\end{array}$ & 2014 & 2015 & 2017 \\
\hline $\mathrm{a} F \mathrm{FO} 4(\AA)$ & $8.410(8)$ & $8.404(6)$ & $8.424(7)$ \\
\hline $\mathrm{a}_{\mathrm{FeO}}(\AA)$ & $4.322(9)$ & $4.314(8)$ & $4.331(9)$ \\
\hline $\mathrm{U}_{\mathrm{Fe} 3 \mathrm{O} 4} \mathrm{Fe}^{+3}$ & 0.006 & $0.006(2)$ & $0.006(1)$ \\
\hline $\mathrm{U}_{\mathrm{Fe} 3 \mathrm{O} 4} \mathrm{Fe}^{+2}$ & 0.005 & $0.005(1)$ & $0.005(1)$ \\
\hline $\mathrm{U}_{\mathrm{FeO}} \mathrm{Fe}^{+2}$ & $0.006(2)$ & $0.006(1)$ & 0.007 (2) \\
\hline $\begin{array}{l}\mathrm{FeO} / \mathrm{Fe}_{3} \mathrm{O}_{4} \\
\text { weight }\end{array}$ & $\begin{array}{l}0.25(3) / \\
0.75(3)\end{array}$ & $\begin{array}{l}0.21(2) / \\
0.79(2)\end{array}$ & $\begin{array}{l}0.19(3) / \\
0.81(3)\end{array}$ \\
\hline $\begin{array}{l}\text { Refined } \\
\text { up to } 25 \AA\end{array}$ & 2014 & 2015 & 2017 \\
\hline $\mathrm{a}_{\mathrm{Fe} 3 \mathrm{O} 4}(\AA)$ & $8.427(3)$ & $8.416(2)$ & $8.422(9)$ \\
\hline $\mathrm{a} F e O(\AA)$ & $4.298(3)$ & $4.289(3)$ & $4.330(9)$ \\
\hline $\mathrm{U}_{\mathrm{Fe} 3 \mathrm{O} 4} \mathrm{Fe}^{+3}$ & 0.008 & $0.008(1)$ & $0.005(1)$ \\
\hline $\mathrm{U}_{\mathrm{Fe} 3 \mathrm{O} 4 \mathrm{Fe}^{+2}}$ & $0.012(2)$ & $0.013(1)$ & $0.012(1)$ \\
\hline $\mathrm{U}_{\mathrm{FeO}} \mathrm{Fe}^{+2}$ & $0.009(2)$ & 0.009 (1) & $0.008(2)$ \\
\hline $\begin{array}{l}\mathrm{FeO} / \mathrm{Fe}_{3} \mathrm{O}_{4} \\
\text { weight }\end{array}$ & $\begin{array}{l}0.23(2) / \\
0.77(2)\end{array}$ & $\begin{array}{l}0.20(2) / \\
0.80(2)\end{array}$ & $\begin{array}{l}0.23(2) / \\
0.77(2)\end{array}$ \\
\hline
\end{tabular}


Rodrigo U. Ichikawa, Alejandro G. Roca*, Alberto López-Ortega, Marta Estrader, Inma Peral, Xabier Turrillas and Josep Nogués

Combining X-ray Whole Powder Pattern Modeling, Rietveld and Pair Distribution Function analyses as a novel bulk approach to study interfaces in heteronanostructures: Oxidation front in $\mathrm{FeO} / \mathrm{Fe}_{3} \mathrm{O}_{4}$ core/shell nanoparticles as a case study
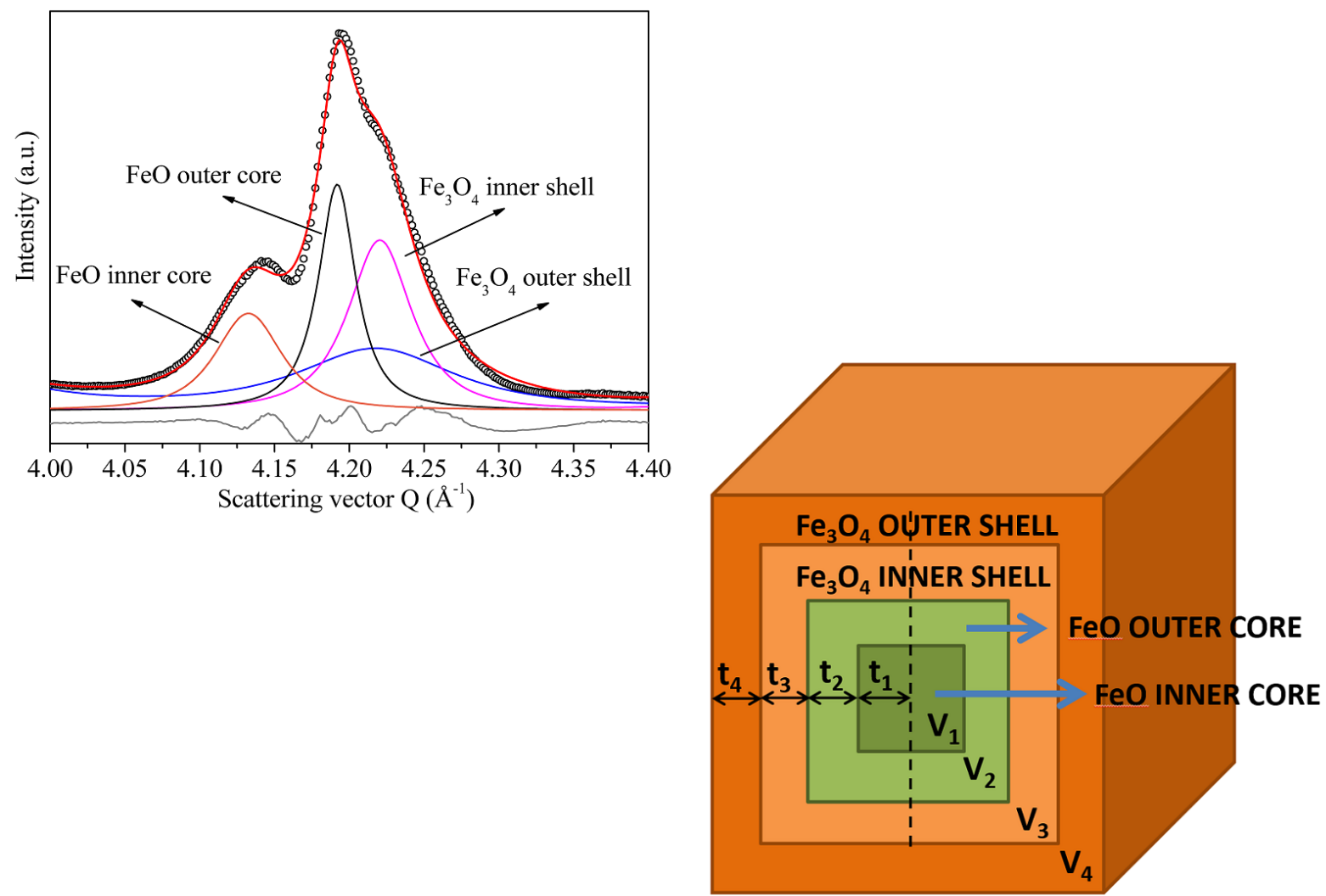

The temporal evolution of $\mathrm{FeO} / \mathrm{Fe}_{3} \mathrm{O}_{4}$ nanoparticle microstructure can be modelled from synchrotron X-ray diffraction measurements using a bulk approach combining whole powder pattern modeling, Rietveld and pair distribution function. The model consists on $\mathrm{Fe}_{3} \mathrm{O}_{4}$-outer and inner shell and $\mathrm{FeO}$ outer and inner shell layers displayed in an onion-type structure. This approach facilitates the study of averaged interfaces in different type of heterostructures.

Keyword: Heterostrutures 
Copyright WILEY-VCH Verlag GmbH \& Co. KGaA, 69469 Weinheim, Germany, 2016.

Supporting Information

Combining X-ray Whole Powder Pattern Modeling, Rietveld and Pair Distribution Function analyses as a novel bulk approach to study interfaces in heteronanostructures: Oxidation front in $\mathrm{FeO} / \mathrm{Fe}_{3} \mathrm{O}_{4}$ core/shell nanoparticles as a case study

Rodrigo U. Ichikawa, Alejandro G. Roca* Alberto López-Ortega, Marta Estrader, Inma Peral, Xabier Turrillas and Josep Nogués 


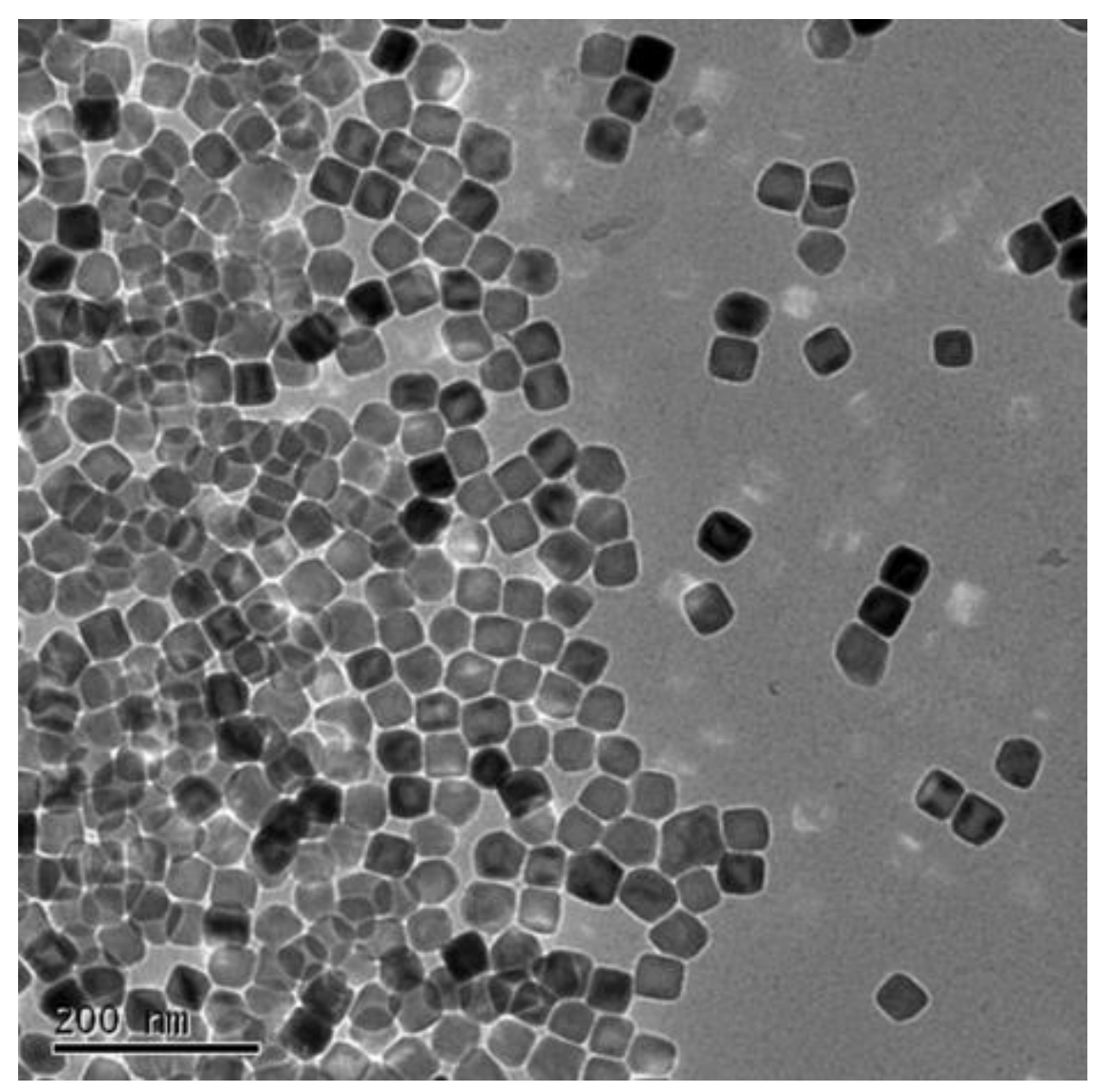

Figure S1. Low magnification TEM image of the nanoparticles. Note that small tilts of the nanoparticles with respect to the electron beam may strongly influence the core/shell contrast. 


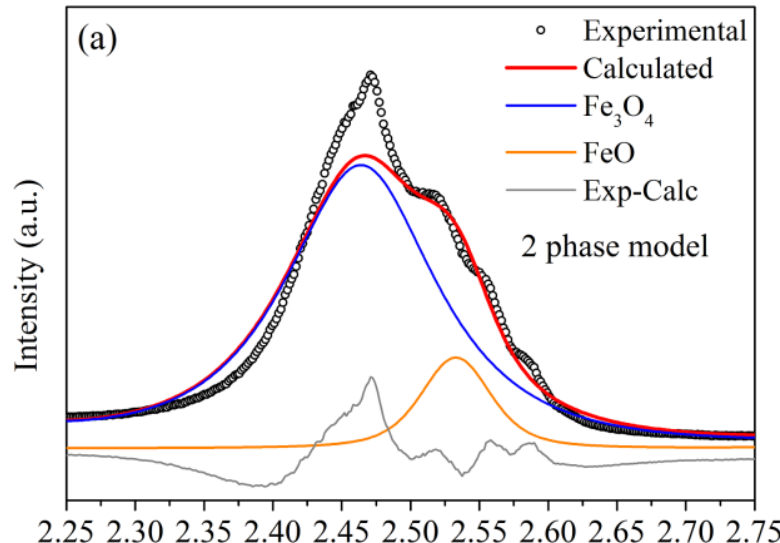

Scattering vector $\mathrm{Q}\left(\AA^{-1}\right)$

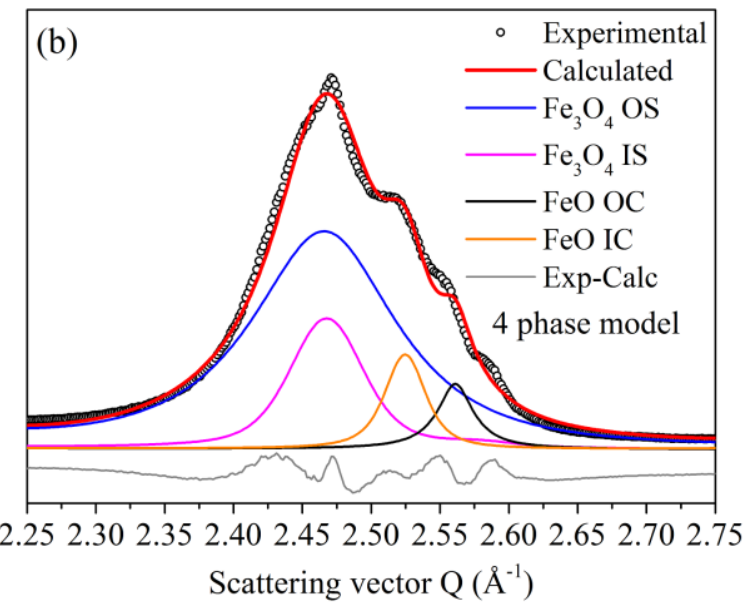

Figure S2. WPPM fitting at the $2.5 \AA^{-1}$ region that presents a superposition of the $\left[\begin{array}{lll}3 & 1 & 1\end{array}\right]$ $\mathrm{Fe}_{3} \mathrm{O}_{4}$ and [111] $\mathrm{FeO}$ diffraction peaks using either (a) two phases $\left(\mathrm{Fe}_{3} \mathrm{O}_{4}+\mathrm{FeO}\right)$, (b) four phases $\left(\mathrm{Fe}_{3} \mathrm{O}_{4}\right.$-outer shell/ $\mathrm{Fe}_{3} \mathrm{O}_{4}$-inner shell/FeO-outer core/FeO-inner core). Black dots: experimental data, red line: fitted profile, grey line: difference between experimental and calculated profiles. 

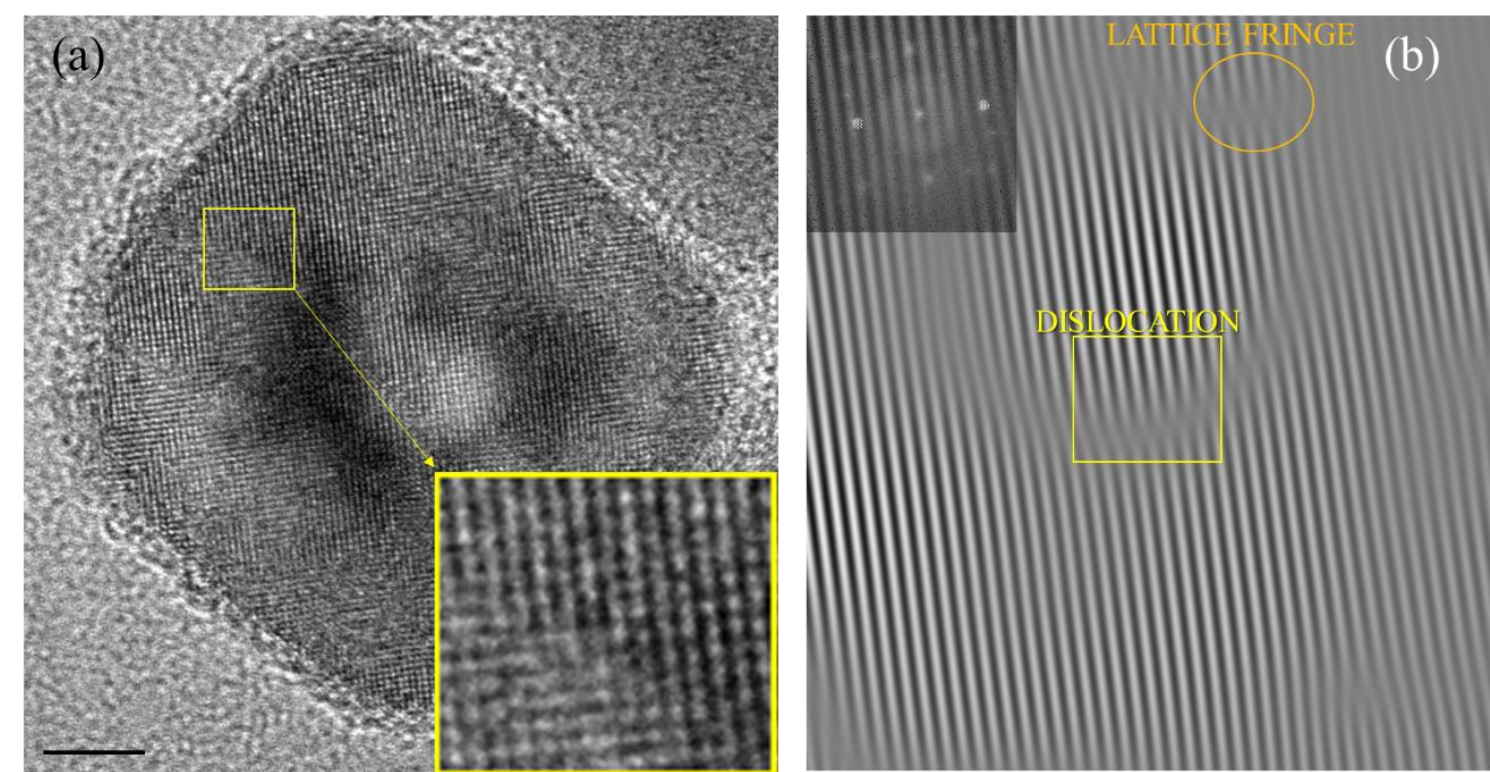

Figure S3. a) HR-TEM image of one nanocube (scale bar $=5 \mathrm{~nm}$ ). The inset reveals the formation of dislocations; b) Inversed FFT of the zoomed area using the (220) spot, highlighting the presence of some defects. 
Table S1. Rietveld refinements results for cell parameters (a in $\AA$ ) and global atomic displacement factors ( $U$ in $\AA^{2}$ ).

\begin{tabular}{|c|c|c|c|c|}
\hline $\mathrm{Fe}_{3} \mathrm{O}_{4} \mathrm{OS}$ & 2013 & 2014 & 2015 & 2017 \\
\hline $\mathrm{a}$ & $8.3990(8)$ & $8.3990(4)$ & $8.3990(4)$ & $8.3990(6)$ \\
\hline $\mathrm{U}$ & \multicolumn{4}{|c|}{$0.005(1)$} \\
\hline $\mathrm{Fe}_{3} \mathrm{O}_{4} \mathrm{IS}$ & 2013 & 2014 & 2015 & 2017 \\
\hline $\mathrm{a}$ & $8.3902(4)$ & $8.3950(4)$ & $8.3950(7)$ & $8.3950(5)$ \\
\hline $\mathrm{U}$ & \multicolumn{4}{|c|}{$0.009(2)$} \\
\hline $\mathrm{FeO} \mathrm{OC}$ & 2013 & 2014 & 2015 & 2017 \\
\hline $\mathrm{a}$ & $4.2405(7)$ & $4.2271(9)$ & $4.2166(2)$ & $4.2213(8)$ \\
\hline $\mathrm{U}$ & \multicolumn{4}{|c|}{$0.005(1)$} \\
\hline $\mathrm{x}$ & 0.80 & 0.78 & 0.75 & 0.76 \\
\hline $\mathrm{FeO}$ IC & 2013 & 2014 & 2015 & 2017 \\
\hline $\mathrm{a}$ & $4.2999(5)$ & $4.2890(8)$ & $4.2836(8)$ & $4.2874(7)$ \\
\hline $\mathrm{U}$ & \multicolumn{4}{|c|}{$0.006(1)$} \\
\hline $\mathrm{x}$ & 0.93 & 0.91 & 0.89 & 0.90 \\
\hline
\end{tabular}

The Rietveld refinement was performed taking into account absorption, since the experimental data were collected in transmission geometry. The cell parameters of the two FeO phases as for WPPM are different and present a temporal evolution. For NC2013, the FeO core is closer to stoichiometric FeO, while the outer core has a composition of $\mathrm{Fe}_{0.80} \mathrm{O}$. Again, the use of two phases for wüstite reinforces that oxidation is present for $\mathrm{FeO}$. Note that since when refined individually non-physical values were found for the global atomic displacement factors, $\mathrm{U}$, they were refined globally. Interestingly, $\mathrm{U}$ for both the $\mathrm{Fe}_{3} \mathrm{O}_{4}$ and $\mathrm{FeO}$ phases remain constant over time, indicating that disordering within the phases does not significantly increase with time. 

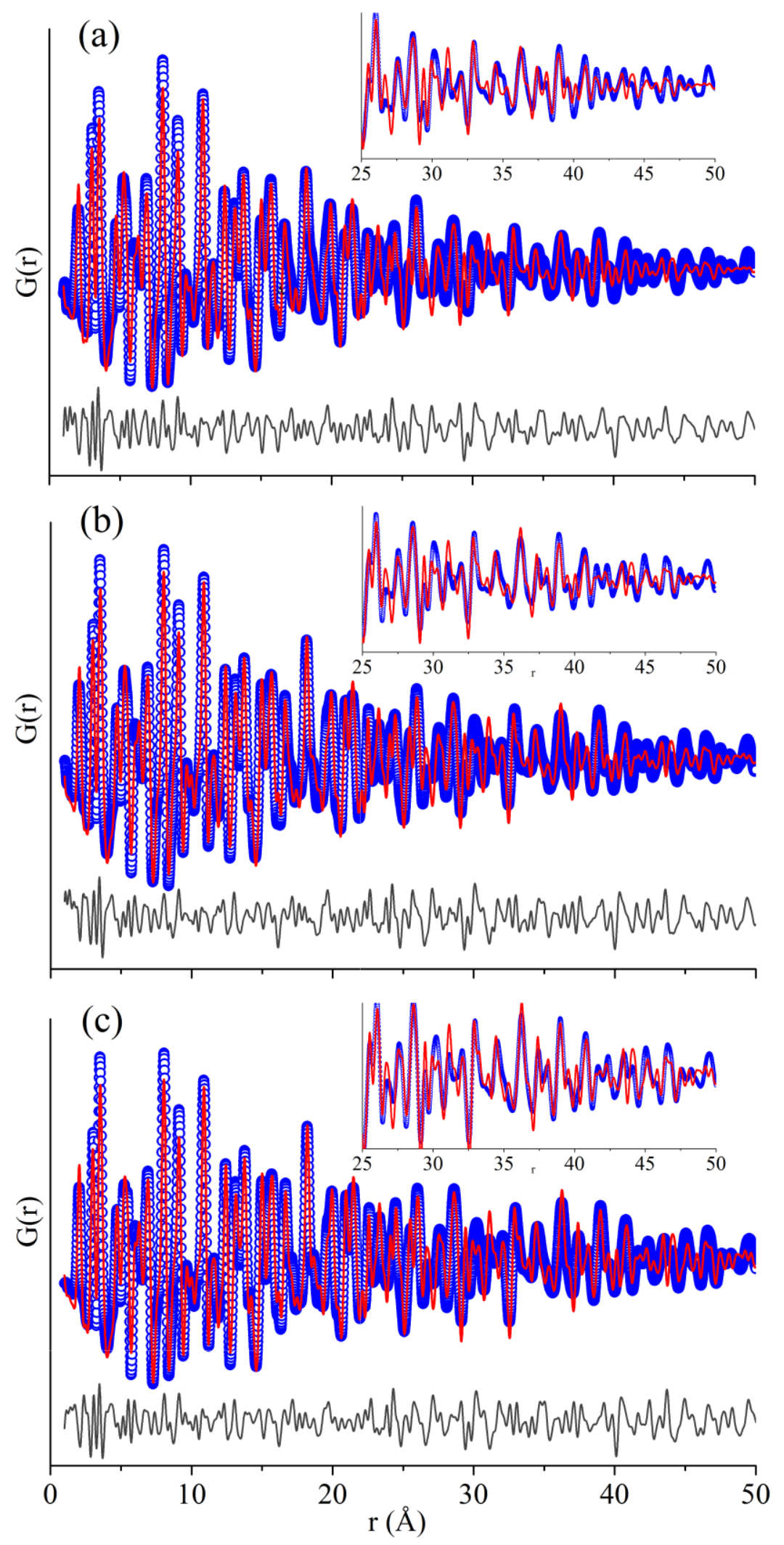

Figure S4. X-ray PDF data modeling, i.e., dependence of PDF function $G$ on the radial distance r, for the (a) NC2014, (b) NC2015 and (c) NC2017 samples up to $50 \AA$. Blue dots: experimental data, red line: PDF modelling, gray line: difference between the modelling and the experimental data. 


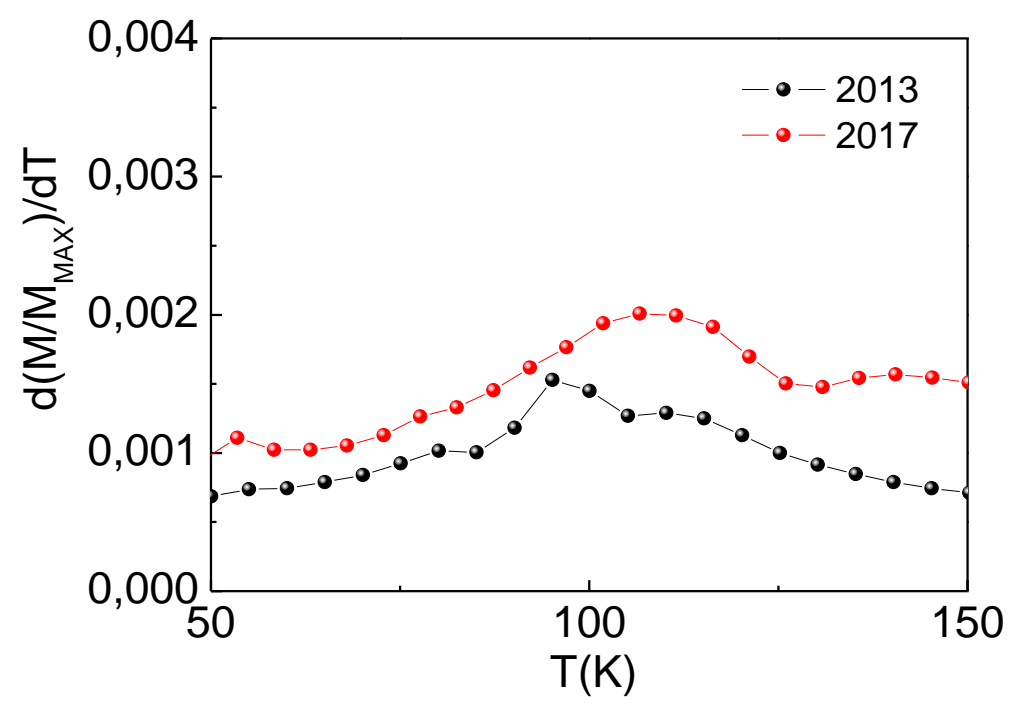

Figure S5. Derivative of M(T) close to the Verwey transition for the NC2013 and NC2017 samples. 

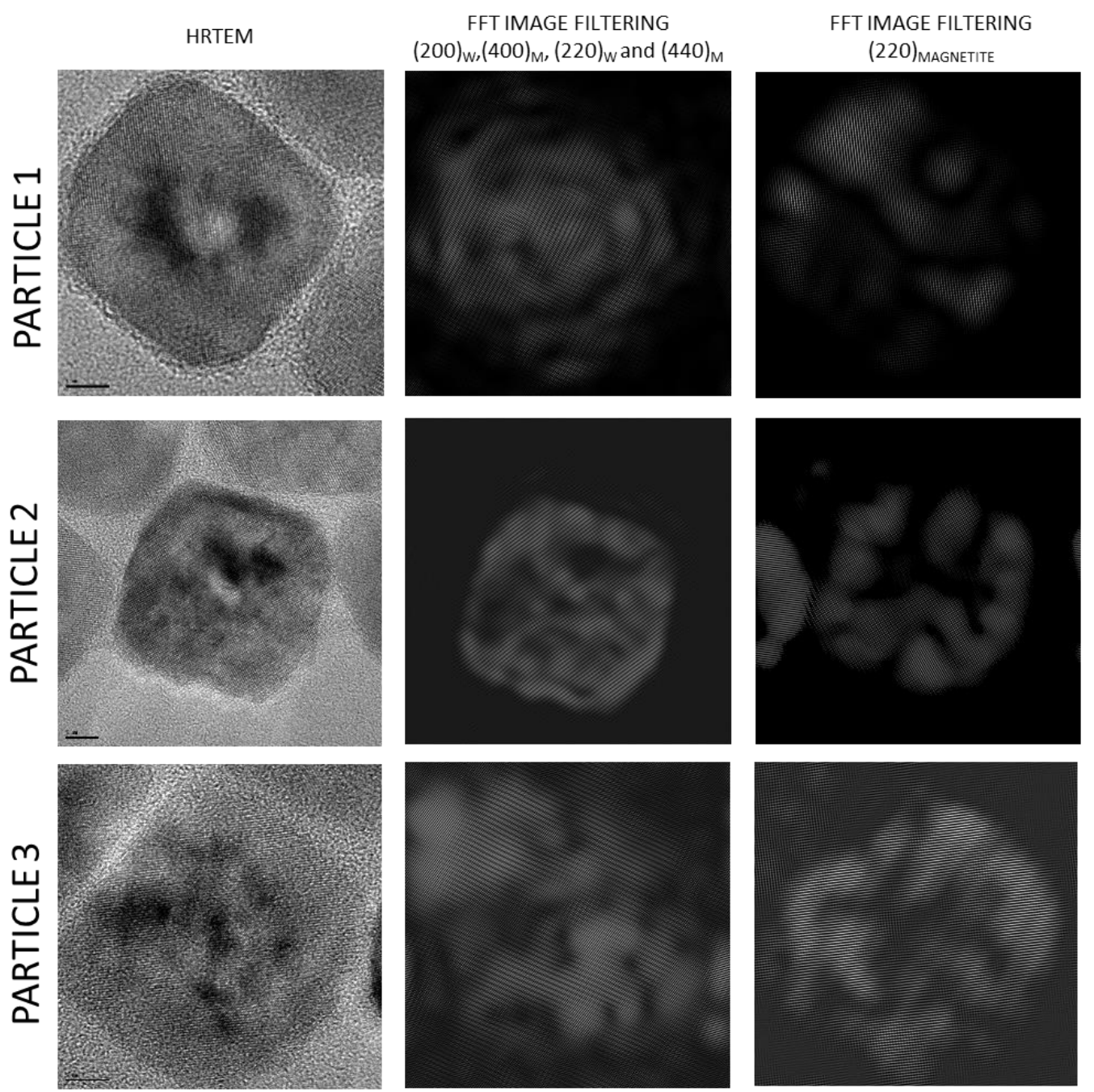

Figure S6. Left - HRTEM images of theree different particles of the NC 2017 sample (scale bar - $5 \mathrm{~nm}$ ). Center - Inverse-FFT image obtained after filtering the planes shared between wüstite and magnetite [i.e., $(200)_{\mathrm{w}},(400)_{\mathrm{m}},(220)_{\mathrm{w}}$ and $(440)_{\mathrm{m}}$ reflections]. Right - InverseFFT image obtained after filtering the $(220)_{\mathrm{m}}$ reflections.

To shed light about the complex crystal structure of the nanoparticles, we have further analyzed the HRTEM images of the nanoparticles. The Fast Fourier Transform (FTT) of the HR images was filtered by (i) the reflections that wüstite and magnetite share, and (ii) the main reflection of magnetite which is only attributed to magnetite and reconstructed back to real-space -inverse-FFT- (see Figure S6). For the (220) reflection of magnetite a mosaic-like structure with a significant amount of phase boundaries can be observed. Note that many of the crystallites seem to be rather spherical-like, in concordance with the results from the WPPM analysis. However, in the case of wüstite and magnetite shared planes, its extension is more homogeneous as it appears spread within the whole particle (as expected from the oxidation process in the $\mathrm{FeO} / \mathrm{Fe}_{3} \mathrm{O}_{4}$ system). Interestingly, it can be observed these features are rather different in the three analyzed particles. This is consistent with the somewhat large value of the standard deviation of the crystallite sizes in the WPPM analysis. 